\title{
Nanofibrous bicomponent scaffolds for the dual delivery of NGF and GDNF: controlled release of growth factors and their biological effects
}

\author{
Chaoyu Liu $\mathbb{1}^{1,2} \cdot$ Xiaohua $\mathrm{Li}^{1,3} \cdot$ Qilong Zhao ${ }^{4}$ Yuancai Xie ${ }^{5} \cdot$ Xumei Yao $^{1} \cdot$ Min Wang $^{2} \cdot$ Fengjun $_{\text {Cao }}^{3}$
}

Received: 17 July 2020 / Accepted: 18 December 2020 / Published online: 20 January 2021

(c) The Author(s) 2021

\begin{abstract}
Electrospun fibrous scaffolds capable of providing dual growth factor delivery in a controlled manner have distinctive advantages for tissue engineering. In this study, we have investigated the formation, structure, and characteristics/properties of fibrous bicomponent scaffolds for the dual delivery of glial cell line-derived neurotrophic factor (GDNF) and nerve growth factor (NGF) for peripheral nerve tissue regeneration. GDNF and NGF were incorporated into core-shell structured poly(lactic-co-glycolic acid) (PLGA) and poly (D,L-lactic acid) (PDLLA) nanofibers, respectively, through emulsion electrospinning. Using dual-source dual-power electrospinning, bicomponent scaffolds composed of GDNF/PLGA fibers and NGF/PDLLA fibers with different fiber component ratios were produced. The structure, properties, and in vitro release behavior of mono- and bicomponent scaffolds were systematically investigated. Concurrent and sustained release of GDNF and NGF from bicomponent scaffolds was achieved and their release profiles could be tuned. In vitro biological investigations were conducted. Rat pheochromocytoma cells were found to attach, spread, and proliferate on all scaffolds. The release of growth factors from scaffolds could induce much improved neurite outgrowth and neural differentiation. GDNF and NGF released from GDNF/PLGA scaffolds and NGF/PDLLA scaffolds, respectively, could induce dosedependent neural differentiation separately. GDNF and NGF released from bicomponent scaffolds exerted a synergistic effect on promoting neural differentiation.
\end{abstract}

These authors contributed equally: Chaoyu Liu, Xiaohua Li

Chaoyu Liu

1cy@ shiningbiotek.com

$\triangle$ Fengjun Cao

hbsycfj@126.com

1 Department of Research and Development, Shenzhen Shiningbiotek Co., Ltd, Shenzhen 518055, P. R. China

2 Department of Mechanical Engineering, The University of Hong Kong, Pokfulam Road, Hong Kong, P. R. China
3 Oncology Center, Hubei University of Medicine, Shiyan 442000, P. R. China

4 Shenzhen Institutes of Advanced Technology, Chinese Academy of Science, Shenzhen 518055, P. R. China

5 Department of Thoracic, Peking University Shenzhen Hospital, Shenzhen 518036, P. R. China 


\section{Graphical Abstract}
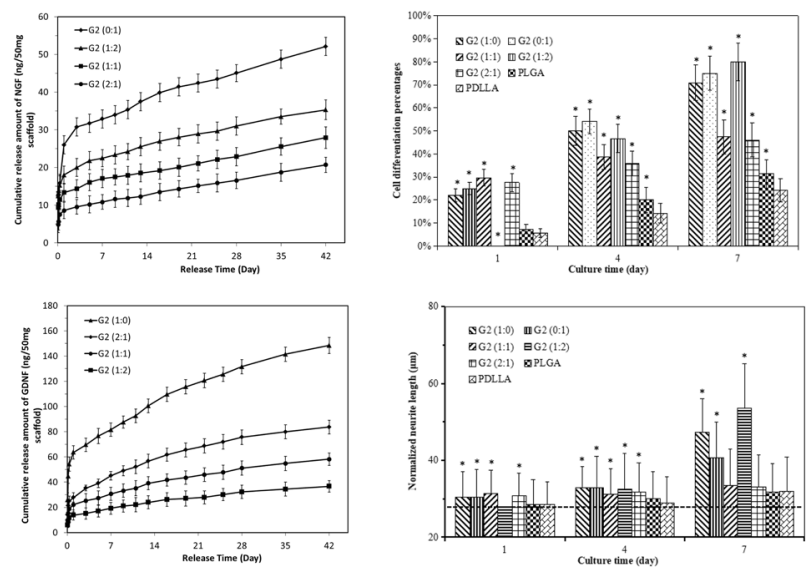

\section{Introduction}

Functional recovery of injured peripheral nerves still needs to be improved in clinic, especially for critical-size peripheral nerve injury. Local delivery of neurotrophic factors including nerve growth factor (NGF) and glial cell line-derived neurotrophic factor (GDNF) at surgical sites have been proposed to enhance peripheral nerve regeneration. These neurotrophic factors play important roles in neuronal survival, neural differentiation, and axonal regeneration independently or synergistically at different effective concentrations [1-5]. Sustained stimulation of neurotrophic factors is also required to induce neural differentiation [6]. However, few studies have been conducted to investigate the influence of dual and sustained neurotrophic factor delivery at biologically effective neurotrophic factor concentrations on neurite outgrowth that may be important for enhanced nerve repair and functional recovery. Suitable delivery vehicles are needed for controlled and sustained delivery of these therapeutic biomolecules due to their vulnerability and short half-life through direct administration [7, 8].

Electrospinning technique is advantageous in producing fibrous scaffolds with micro- to nanoscale architectures resembling extracellular matrix, high surface area to volume ratio, and high porosity. Electrospun fibers with diverse morphology and structures produced by different electrospinning techniques such as emulsion electrospinning and coaxial electrospinning may be utilized as efficient delivery vehicles of various biomolecules for different applications $[9,10]$. The rat pheochromocytoma cell line (PC12 cells) is a widely adopted in vitro model for neuronal differentiation. PC12 cells respond to neurotrophic factors including NGF and GDNF and differentiate into neuron-like phenotypes characterized by halted proliferation and neurite outgrowth $[6,11,12]$.

In this study, bicomponent fibrous scaffolds were designed and fabricated through dual-source dual-power electrospinning (DSDP-ES) technique established in our previous study [13, 14], with GDNF and NGF being incorporated into PLGA and PDLLA nanofibers, respectively, via emulsion electrospinning. The mass ratios of GDNF/PLGA fibers to NGF/PDLLA fibers in bicomponent scaffolds were varied. Dual and sustained release of GDNF and NGF with different release profiles were achieved from scaffolds with different components. The bioactivities of GDNF and NGF released from GDNF/PLGA fibers and NGF/PDLLA fibers were assessed on a culture-to-culture basis using PC12 cells. The cytotoxicity of PC12 cells to different scaffolds was evaluated. The morphology of cells cultured on scaffolds was examined by SEM and confocal laser scanning microscopy (CLSM). Neurite outgrowth and neural differentiation of PC12 cells on different scaffolds were investigated.

\section{Materials and methods}

\subsection{Materials}

PLGA (LA:GA = 50:50) and PDLLA with molecular weight of $100 \mathrm{kDa}$ (as indicated by their inherent viscosity 0.6-0.8 dL/g) were purchased from Lakeshore Biomaterials, USA. Chloroform was supplied by Uni Chem Co., Korea. The human $\beta$-NGF with Enzyme Linked Immunosorbent Assay (ELISA) Kit, human GDNF with ELISA Kit were purchased from Peprotech Inc. and R\&D Systems, Inc., respectively. Dulbecco's Modified Eagle Medium (DMEM), fetal bovine serum (FBS), penicillin/streptomycin $(\mathrm{P} / \mathrm{S})$, and trypsin/EDTA were purchased from Invitrogen, Inc., USA. Mouse anti-neurofilament $(\mathrm{M}+\mathrm{H})$ primary 
antibody, goat anti-mouse IgG secondary antibody (Alexa Fluor 594), phalloidin (Alexa Fluor ${ }^{\circledR} 488$ ), and DAPI (4', 6-diamidino-2-phenylindole) were purchased from Life Technologies. Triton X-100, Span-80, phosphate buffered saline (PBS) tablets, heparin, bovine serum albumin (BSA), paraformaldehyde, glutaraldehyde, sodium cacodylate, MTT (3-(4,5-dimethylthiazol-2-yl)-2,5-diphenyl tetrazolium bromide), and sucrose were Sigma-Aldrich products. Other chemicals were used as received.

\subsection{Fabrication of scaffolds}

The fibrous scaffolds incorporated with GFs were fabricated by emulsion electrospinning technique. For water-in-oil (w/ o) emulsion formulation, PLGA or PDLLA dissolved in chloroform at a certain concentration was used as the oil phase and NGF or GDNF were dissolved in $0.5 \mathrm{wt} \%$ BSA solution as the water phase. The volume ratio of the oil phase to the water phase was fixed at 10:1. $5 \mathrm{wt} \%$. Span- 80 (with respect to the weight of polymer used) was added in the polymer solution for the formation and stabilization of emulsions [14]. The oil phase and water phase were mixed for $10 \mathrm{~min}$ through magnetic stirring at $300 \mathrm{rpm}$ to form homogeneous w/o emulsions. Polymer concentration was optimized for both PLGA and PDLLA and served as control variable to manipulate fiber diameter. The electrospinning parameters including applied voltage, inner diameter of needle tip, needle-to-collector distance, and feeding rate of emulsions were optimized as $16 \mathrm{kV}, 0.8 \mathrm{~mm}, 8 \mathrm{~cm}$, and $2 \mathrm{~mL} / \mathrm{h}$, respectively [14]. To produce fibrous bicomponent scaffolds, DSDP-ES was employed. GDNF/PLGA fibers and NGF/PDLLA fibers were collected simultaneously by a rotating drum collector, forming non-woven bicomponent scaffolds. By using a multiple-syringe strategy, the mass ratio of GDNF/PLGA fibers to NGF/PDLLA fibers in bicomponent scaffolds was adjusted. The formulation of emulsions for producing different mono- and bicomponent scaffolds is summarized in Table 1 . The produced electrospun scaffolds were freeze-dried for $24 \mathrm{~h}$ before any further experiments.

\subsection{Characterization of fibers and electrospun scaffolds}

Morphological and structural characterization of electrospun fibers and fabricated scaffolds was conducted. Freezedried samples of electrospun fibers and scaffolds were sputtered with a thin gold coating for $30 \mathrm{~s}$ by a sputter coater (BEL-TACSCD005) and their morphology was examined using SEM (Hitachi S-4800 FEG SEM, Japan). A total of 100 fibers in each scaffold were randomly selected to determine average fiber diameters. Electrospun fibers were also collected during electrospinning on a copper grid covered with carbon film and their structures were observed using TEM (Philips EM208s TEM, the Netherlands).

\subsection{In vitro release test of NGF and GDNF}

For in vitro release investigations, experiments followed the procedures as used by other research groups [15]. Briefly, each fibrous scaffold with similar thickness was cut into square shape $(30 \times 30 \mathrm{~mm})$ for testing. Scaffold samples (about $50 \mathrm{mg}$ each) were immersed in 12-well plates filled with $3 \mathrm{~mL}$ release medium and incubated in shaking water bath at $37^{\circ} \mathrm{C}$. At pre-set times, $0.4 \mathrm{~mL}$ of supernatant was retrieved from each well and replaced by $0.4 \mathrm{~mL}$ of fresh
Table 1 Composition of emulsions for producing nonwoven mono- and bicomponent electrospun scaffolds

\begin{tabular}{|c|c|c|c|c|}
\hline \multirow[t]{2}{*}{ Scaffold sample } & \multicolumn{2}{|c|}{ PLGA emulsions } & \multicolumn{2}{|c|}{ PDLLA emulsions } \\
\hline & $\begin{array}{l}\text { Water phase } \\
1 \mathrm{ml} \mathrm{H}_{2} \mathrm{O}\end{array}$ & $\begin{array}{l}\text { Oil phase } \\
10 \mathrm{ml} \mathrm{CHCl}_{3}\end{array}$ & $\begin{array}{l}\text { Water phase } \\
1 \mathrm{ml} \mathrm{H}_{2} \mathrm{O}\end{array}$ & $\begin{array}{l}\text { Oil phase } \\
10 \mathrm{ml} \mathrm{CHCl}_{3}\end{array}$ \\
\hline $\begin{array}{l}\text { G1 }(0: 1) \\
\text { G1 }(1: 2) \\
\text { G1 }(1: 1) \\
\text { G1 }(2: 1) \\
\text { G1 }(1: 0)\end{array}$ & $\begin{array}{l}5 \mu \mathrm{g} \text { GDNF } \\
5 \mathrm{mg} \text { BSA }\end{array}$ & $\begin{array}{l}1.5 \text { g PLGA } \\
75 \mu \mathrm{l} \text { Span-80 }\end{array}$ & $\begin{array}{l}5 \mu \mathrm{g} \text { NGF } \\
5 \mathrm{mg} \text { BSA }\end{array}$ & $\begin{array}{l}2 \mathrm{~g} \text { PDLLA } \\
100 \mu \mathrm{l} \mathrm{Span}-80\end{array}$ \\
\hline $\begin{array}{l}\text { G2 }(0: 1) \\
\text { G2 }(1: 2) \\
\text { G2 }(1: 1) \\
\text { G2 }(2: 1) \\
\text { G2 }(1: 0)\end{array}$ & $\begin{array}{l}4 \mu \mathrm{g} \text { GDNF } \\
5 \mathrm{mg} \mathrm{BSA}\end{array}$ & $\begin{array}{l}1.2 \mathrm{~g} \text { PLGA } \\
60 \mu \mathrm{l} \text { Span-80 }\end{array}$ & $\begin{array}{l}3.75 \mu \mathrm{g} \mathrm{NGF} \\
5 \mathrm{mg} \mathrm{BSA}\end{array}$ & $\begin{array}{l}1.5 \text { g PDLLA } \\
75 \mu \mathrm{l} \text { Span-80 }\end{array}$ \\
\hline PLGA & $5 \mathrm{mg}$ BSA & $\begin{array}{l}1.5 \text { g PLGA } \\
75 \mu 1 \text { Span-80 }\end{array}$ & & \\
\hline PDLLA & & & $5 \mathrm{mg}$ BSA & $\begin{array}{l}1.5 \mathrm{~g} \text { PDLLA } \\
75 \mu \mathrm{l} \text { Span-80 }\end{array}$ \\
\hline
\end{tabular}


release medium. The supernatant sample was frozen at $-20{ }^{\circ} \mathrm{C}$ for further measurement or directly used for analysis. The concentration of growth factor in the supernatant was determined using ELISA kit. The release medium was prepared by adding $0.5 \%$ BSA, $0.05 \%$ Tween-20, $0.02 \%$ $\mathrm{NaN}_{3}$, and $0.1 \%$ heparin in PBS solution. At least three replicates were tested for each type of fibrous scaffold and results were expressed as mean $\pm \mathrm{SD}$.

\subsection{Cell culture}

PC12 cells (rat pheochromocytoma cell line, Biowit Technologies, Shenzhen, China) were used for determining the bioactivity of growth factors, cytotoxicity of fibrous scaffolds, and cell proliferation and differentiation on scaffolds. All in vitro experiments used PC12 cells cultured in DMEM culture medium supplemented with glucose $(2 \mathrm{~g} / \mathrm{L}), 10 \% \mathrm{FBS}$, and $1 \% \mathrm{P} / \mathrm{S}$ antibiotics at $37^{\circ} \mathrm{C}$ in humidified air containing $5 \% \mathrm{CO}_{2}$ unless noted otherwise. When the cells cultured in a flask achieved $80 \%$ confluence, they were enzymatically digested by $0.25 \%(\mathrm{w} / \mathrm{v})$ trypsin-EDTA from the culture flask, and counted using a haemocytometer for further experiments. At least three replicates were tested for each type of fibrous scaffold and results were expressed as mean \pm SD.

\subsection{Evaluation of cytotoxicity of fibrous scaffolds}

In vitro cytotoxicity of fibrous scaffolds was investigated by using MTT assay. Fibrous scaffolds were cut into square shape $(0.8 \times 0.8 \mathrm{~cm})$, sterilized by ${ }^{60} \mathrm{Co} \gamma$-irradiation at a dose of $15 \mathrm{kGy}$ and then placed in the wells of 96-well plates. Cells were seeded on the scaffolds at initial density of $4 \times 10^{3}$ cells/well in $200 \mu \mathrm{L}$ of growth medium and incubated in a $5 \% \mathrm{CO}_{2}$ humidified atmosphere at $37^{\circ} \mathrm{C}$. The culture medium was refreshed every 2 days. Cells cultured in culture medium were used as control. The cytotoxicity at days 1,4 , and 7 was evaluated. In all, $10 \mu \mathrm{L}$ of MTT solution $(5 \mathrm{mg} / \mathrm{mL})$ in PBS was added to each well, and the plate was incubated for $4 \mathrm{~h}$ in a $5 \% \mathrm{CO}_{2}$ humidified atmosphere at $37^{\circ} \mathrm{C}$. In all, $100 \mu \mathrm{L}$ of DMSO was added, and the plates were shaken for $15 \mathrm{~min}$ at $37^{\circ} \mathrm{C}$ by a shaker incubator to dissolve the formazan crystals. In all, $100 \mu \mathrm{L}$ of solution in each well was pipetted and transferred to a 96-well plate. The absorbance at $570 \mathrm{~nm}$ of each well was measured using a plate reader. The cell viability was calculated using the equation as below:

$$
\text { Cell Viability }(\%)=\mathrm{OD}_{570(\text { sample })} / \mathrm{OD}_{570(\text { control })} \times 100 \% \text {, }
$$

where $\mathrm{OD}_{570 \text { (sample) }}$ represented measurement of optical density from the wells loaded with fibrous scaffolds and $\mathrm{OD}_{570 \text { (control) }}$ from the wells without scaffolds. At least three replicates were tested for each type of fibrous scaffold and results were expressed as mean $\pm \mathrm{SD}$.

\subsection{Cell proliferation and differentiation on fibrous scaffolds}

The cell response on fibrous scaffolds including cell proliferation and differentiation was investigated. Briefly, electrospun scaffold samples with or without growth factors were cut into square shape $(2.5 \times 2.5 \mathrm{~cm}$, about $5 \mathrm{mg})$ and sterilized. The scaffold samples were placed in the wells of 12 -well culture plates and covered the bottom of each well. About $4 \times 10^{3}$ PC12 cells were seeded on the fibrous scaffolds in each well supplemented with $1 \mathrm{~mL}$ culture medium in a $5 \% \mathrm{CO}_{2}$ humidified atmosphere at $37^{\circ} \mathrm{C}$. The culture medium was refreshed every 2 days. After 1, 4, and 7 days of culture, the cell-scaffold constructs were washed twice with PBS and fixed with $4 \%$ PFA for $10 \mathrm{~min}$ at room temperature. After washing twice with $\mathrm{PBS}$, the cells were permeabilized with $0.1 \%$ Triton $\mathrm{X}-100$ solution and incubated in $(1 \% \mathrm{w} / \mathrm{v}) \mathrm{BSA}$ block solution for $30 \mathrm{~min}$, followed by the incubation in mouse anti-neurofilament $(\mathrm{M}+\mathrm{H})$ primary antibody (1:100 dilution) containing block solution for $1 \mathrm{~h}$. After washing two times with PBS, the cells were incubated with goat anti-mouse IgG secondary antibody ( 2 drops $/ \mathrm{mL}$ ) for $30 \mathrm{~min}$. FITC phalloidin (1:40 dilution) was simultaneously added for F-actin staining for $30 \mathrm{~min}$ and DAPI (1:1000 dilution) was added for nuclei staining for $5 \mathrm{~min}$. Confocal imaging of cells on scaffolds was performed on a confocal microscope (LSM 710, Carl Zeiss).

The morphology of cell-scaffold constructs was studied under SEM. In order to prepare the samples for SEM examination, the cell-scaffold constructs were washed with PBS and subsequently fixed with $2.5 \%$ glutaraldehyde at $4{ }^{\circ} \mathrm{C}$ for $4 \mathrm{~h}$. After washing with cacodylate buffer containing 0.1 M sucrose, they were further washed with PBS and rinsed with DI water. The cell-scaffold constructs were collected after freeze-drying for $48 \mathrm{~h}$, sputter-coated with a thin layer of gold for $30 \mathrm{~s}$ and then observed under SEM. At least three replicates were tested for each type of fibrous scaffold and results were expressed as mean \pm SD.

\subsection{Image analysis}

SEM images were loaded into Image J (National Institute of Health, USA) and 100 fibers in each scaffold were randomly selected to determine average fiber diameters. Confocal microscopic images were loaded into Image $\mathbf{J}$ and morphometric data were obtained. The presence of neurites was examined and cell differentiation was quantified by measuring the neurite length. Only protrusions originating from the cell body and longer than $28 \mu \mathrm{m}$ (about two times of average cell body diameter) were counted as neurites. 


\section{Results}

\subsection{Morphology and structure of fibrous scaffolds incorporated with growth factors}

PLGA and PDLLA-based mono- and bicomponent nanofibrous scaffolds with a thickness of approximate $400 \mu \mathrm{m}$ were obtained through DSDP-ES technique and emulsion electrospinning. The surface morphology of fibrous scaffolds was examined by SEM and is shown in Fig. 1a. Mono- and bicomponent fibrous scaffolds exhibited non-woven structures of randomly orientated fibers. Porous structure was formed by robust and beadless fibers with smooth surface. The distribution of fibers in bicomponent scaffolds appeared to be random.

Through emulsion electrospinning, core-shell structure was formed in both GDNF/PLGA fibers and NGF/PDLLA fibers, which is shown in Fig. 1b. The water phase core that was enclosed by oil phase shell is marked by dotted ellipse. The core-shell structure existed with discontinuous water phase core in both types of fibers but appeared differently. The phase boundary of core-shell structure in PDLLA fibers was unambiguous, while it appeared in a dispersive pattern in PLGA fibers.

Fiber diameter of various scaffolds was varied by changing polymer concentration during emulsion electrospinning, which was summarized in Fig. 2. The fibrous scaffolds were divided into thick fiber (G1) and thin fiber (G2) groups. The average fiber diameter decreased in both G1 and G2 groups as component ratio of GDNF/PLGA fibers to NGF/PDLLA fibers increased from 0:1 to 1:0.

\subsection{In vitro release profiles of NGF and GDNF}

The cumulative release of NGF and GDNF from electrospun scaffolds within a 42-day test are demonstrated in Figs. 3 and 4.

As for the release behavior of NGF, all scaffolds exhibited similar release profile including an initial burst release within $24 \mathrm{~h}$, followed by a much slower and sustained release. After 6-week release, the cumulative release amount of NGF increased to $29.7 \pm 2.2,21.1 \pm 2.4,16.4 \pm$ 2.0 , and $12.5 \pm 2.9 \mathrm{ng}$ in G1 group and $52.1 \pm 2.4,35.3 \pm$ $2.6,27.9 \pm 2.9$, and $20.7 \pm 2.0 \mathrm{ng}$ in G2 group, corresponding to GDNF/PLGA fiber to NGF/PDLLA fiber ratio at $0: 1,1: 2,1: 1$, and $2: 1$, respectively. The results indicated that cumulative release amount of NGF increased generally with the decrease of GDNF/PLGA fiber to NGF/PDLLA fiber ratio for bicomponent scaffolds. Thinner fiber diameter (G2 group) resulted in more cumulative release amount of growth factors comparing with G1 group at certain GDNF/ PLGA fiber to NGF/PDLLA fiber ratio.

A much faster release behavior was observed for GDNF. After an initial burst release within $24 \mathrm{~h}$, a sustained release of
GDNF was observed. After 6-week release, the cumulative release amount of GDNF increased to $112.0 \pm 6.0,57.5 \pm 5.4$, $40.0 \pm 5.1$, and $25.0 \pm 4.6 \mathrm{ng}$ in G1 group and $148.4 \pm 6.5$, $83.7 \pm 5.4,58.2 \pm 4.9$, and $36.6 \pm 4.6 \mathrm{ng}$ in G2 group, corresponding to GDNF/PLGA fiber to NGF/PDLLA fiber ratio at $1: 0,2: 1,1: 1$, and $1: 2$, respectively. The results indicated that cumulative release amount of GDNF from scaffolds increased with the increase of GDNF/PLGA fiber to NGF/PDLLA fiber ratio but with the decrease of fiber diameter. An increase in GNDF release rate was noticed at around 2 weeks of in vitro release, which was particularly obvious in G1 (1:0) scaffolds. The results of in vitro release tests revealed that concurrent and sustained release of NGF and GDNF from bicomponent scaffolds could be successfully achieved using bicomponent scaffolds made by DSDP-ES. The release rate of GDNF was much faster than that of NGF. Thicker fiber diameter could help alleviate the initial burst release and slow down the release rate of both growth factors. Cumulative release amount of NGF and GDNF and their ratios could be tuned by varying GDNF/PLGA fiber to NGF/PDLLA fiber ratios.

\subsection{Evaluation of cytotoxicity of fibrous scaffolds}

The influence of different scaffolds on cell proliferation was evaluated by MTT method and is shown in Fig. 5. The cell proliferation on different scaffolds and petri dish (control) was more or less the same at day 1 . Much improved cell proliferation on scaffolds was observed in all groups at days 4 and 7. At day 4, enhanced cell proliferation was observed on all scaffolds except G2 (1:2) and G2 (2:1) scaffolds as compared to control group. The degree of cell proliferation on PLGA scaffolds was higher as compared to that on PDLLA scaffolds. The highest cell proliferation was found in G2 (1:0) scaffolds and the least proliferation was in G2 (1:2). The cell proliferation on other scaffolds varied with growth factor concentrations and component ratios of GDNF/PLGA fibers to NGF/PDLLA fibers. At day 7, less cell proliferation was observed on all scaffolds except G2 (1:0) scaffolds as compared to control group. The degree of cell proliferation on PLGA scaffolds was higher as compared to that on PDLLA scaffolds. The cell proliferation in different groups was also dependent on growth factor concentrations and component ratios of GDNF/PLGA fibers to NGF/PDLLA fibers. Comparatively lower cell proliferation was observed on bicomponent scaffolds in G2 group that might be attributed to cell differentiation due to growth factors released from scaffolds. All scaffolds exhibited no or negligible cytotoxicity.

\subsection{Morphology of PC12 cells on scaffolds}

The morphology of PC12 cells cultured on different scaffolds for 1, 4, and 7 days were investigated by CLSM and are shown in Figs. 6-8. 
(a)
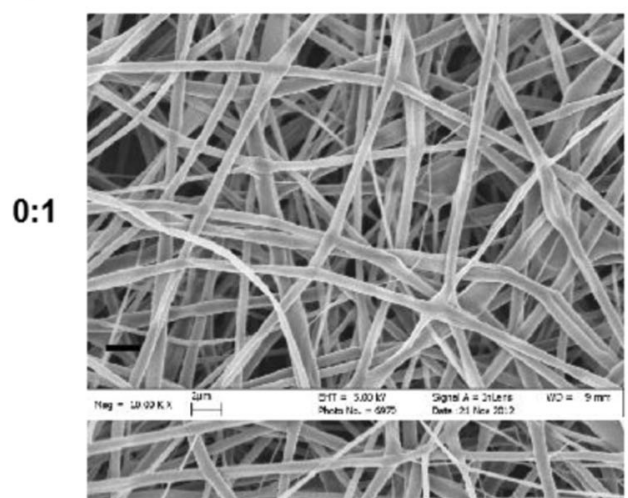

1:2
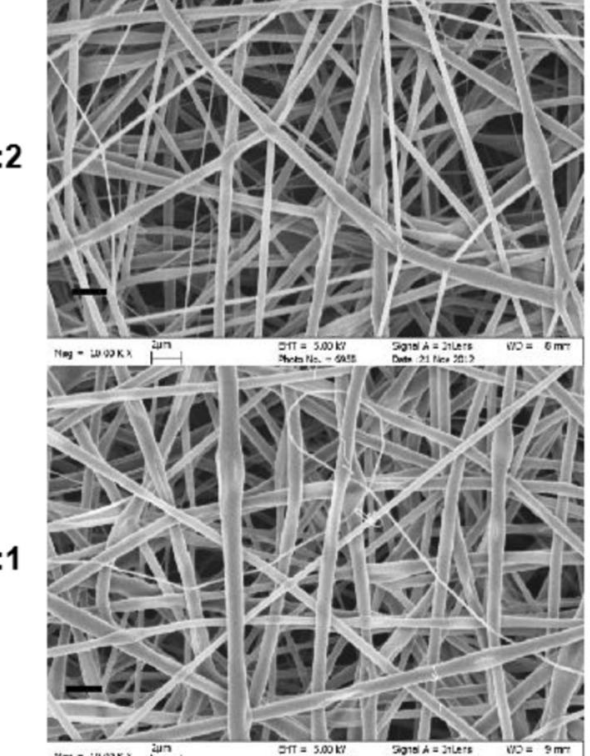

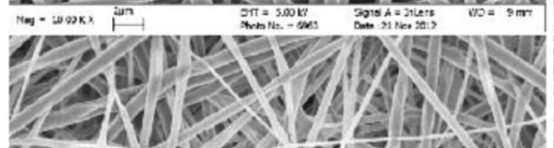
1090.010

2:1
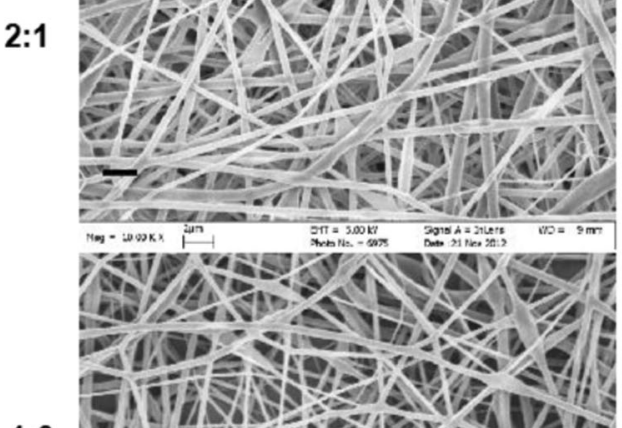

1:0

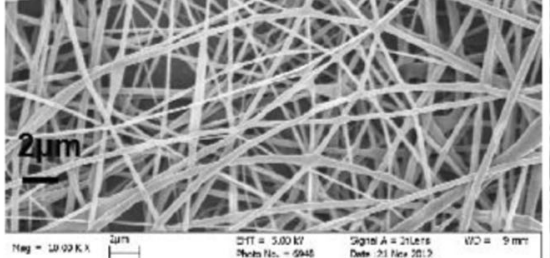

(b)
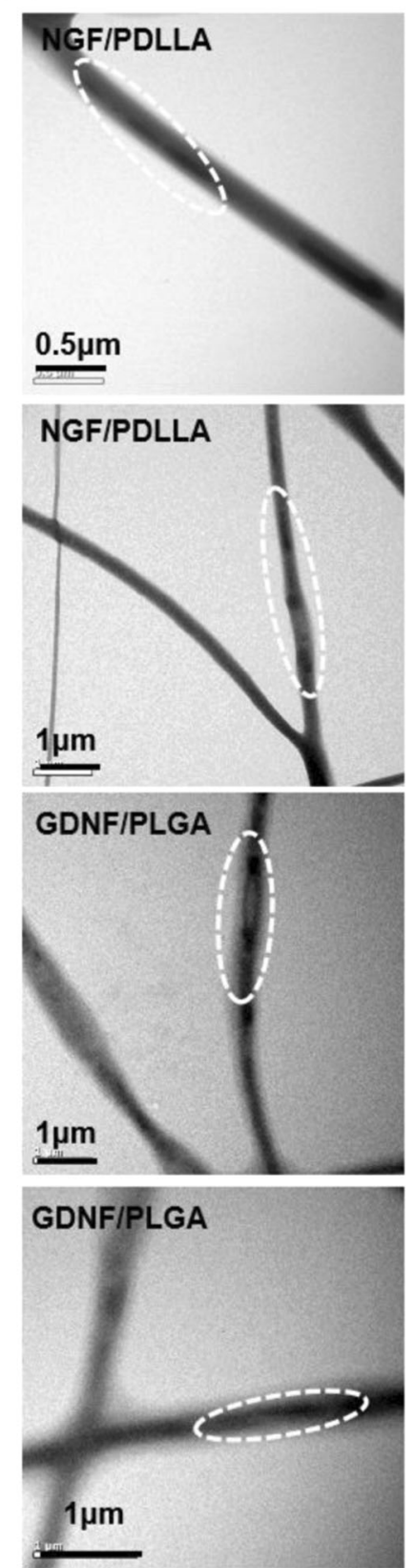

Fig. 1 Morphology and structures of electrospun fibers and scaffolds. a SEM images of mono- and bicomponent fibrous scaffolds, $\mathbf{b}$ TEM images of core-shell structured NGF/PDLLA and GDNF/PLGA fibers and discontinuous core-shell structures were noted with dashed ellipse 


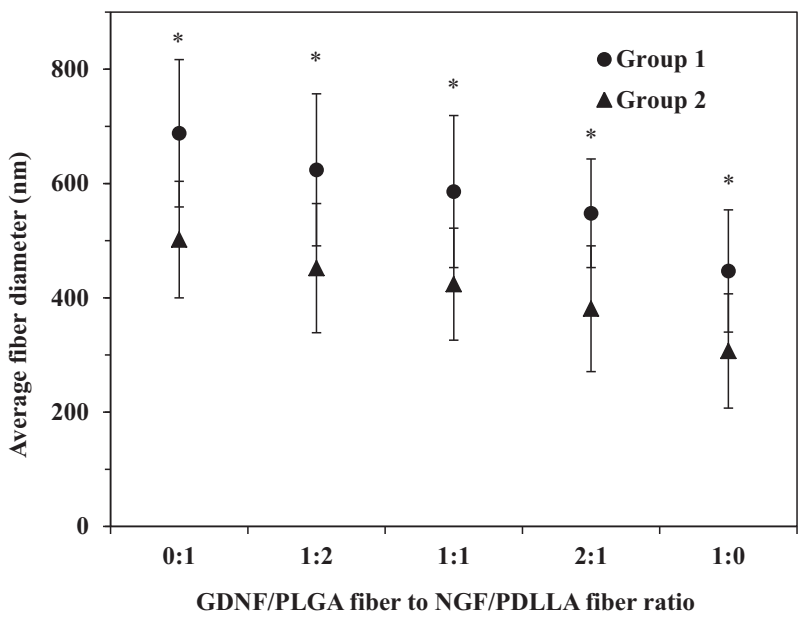

Fig. 2 Average fiber diameter in fibrous scaffolds with different fiber component ratios. Fiber diameter in Group 1 statistically different than that in Group 2 for respective fiber component ratios. ${ }^{*} p<0.05$
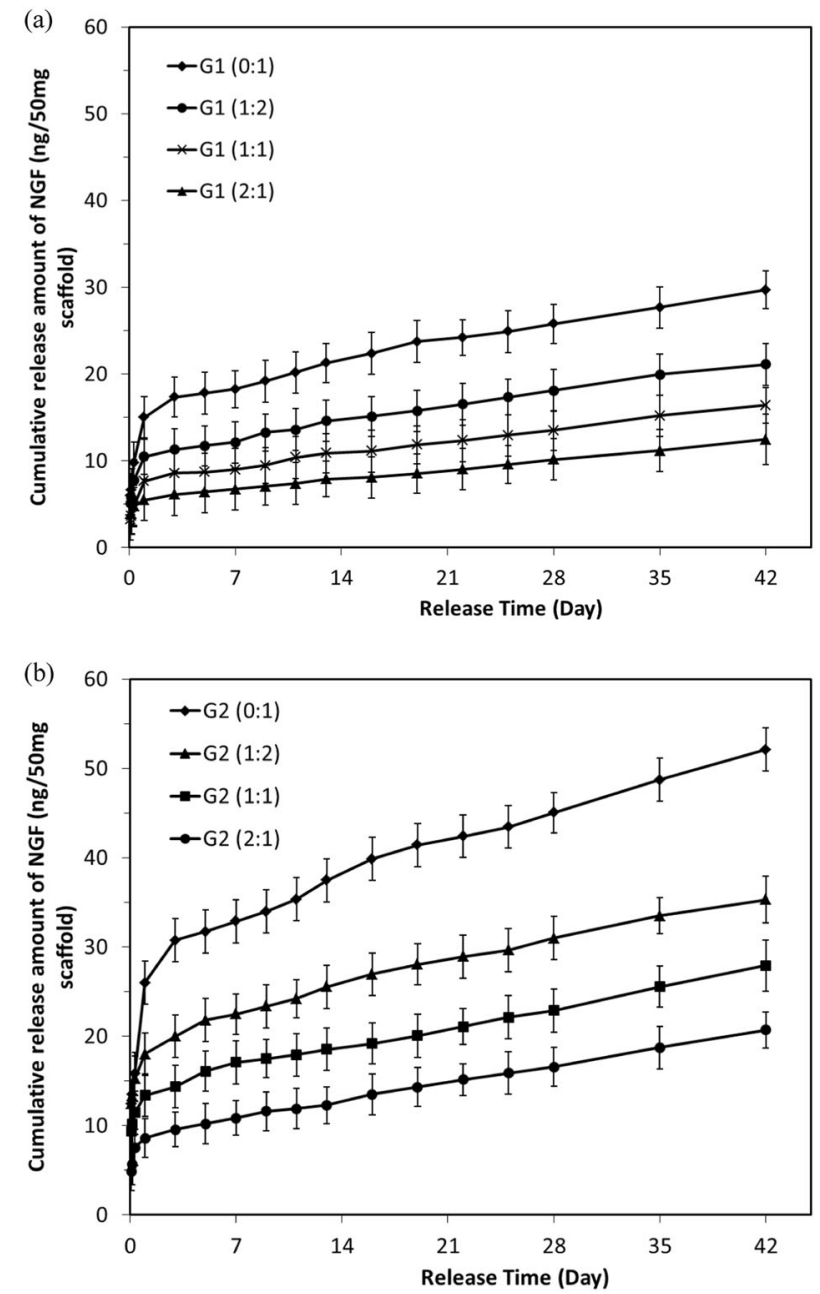

Fig. 3 In vitro release of NGF from electrospun scaffolds in 42-day release tests. a Group 1, b Group 2
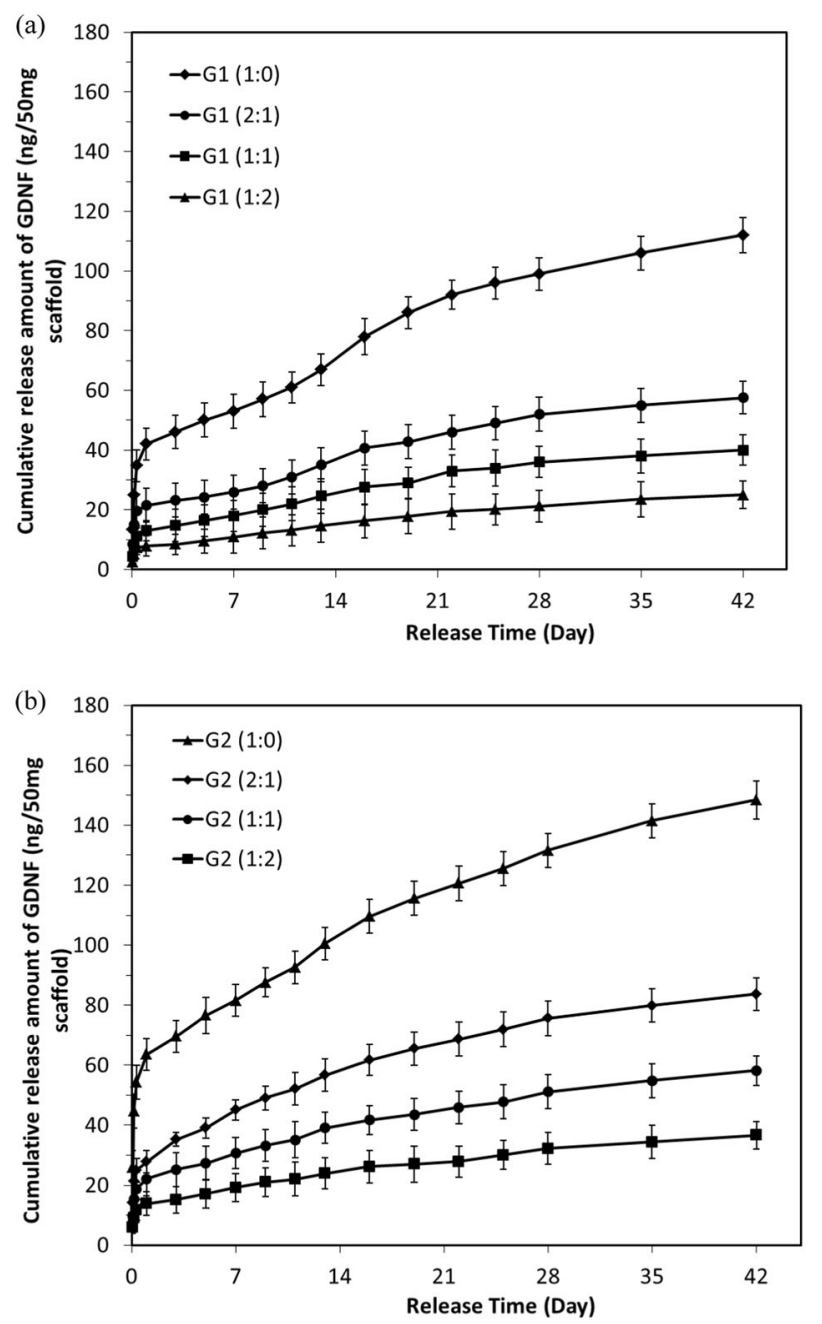

Fig. 4 In vitro release of GDNF from electrospun scaffolds in 42-day release tests. a Group 1, b Group 2

After 1-day culture, PC12 cells randomly scattered on scaffolds with low cell density. Cells on PLGA scaffolds (Fig. 6f) exhibited better cell attachment and cell spreading as compared to those on PDLLA scaffolds (Fig. 61). Most of the cells on PDLLA scaffolds were in spherical shape with little or no neurite sprouting. A few cells on PLGA scaffolds exhibited elongated elliptical shape and initiated neurite sprouting and extension. Improved cell attachment and cell spreading on scaffolds in G1 group (Fig. 6a-e) were observed as compared to that in PDLLA scaffolds. More cells initiating neurite sprouting and exhibiting neurite elongation were found on scaffolds in G1 group except G1 (1:2) scaffolds as compared with both PLGA and PDLLA scaffolds. Neurite sprouting and elongation of PC12 cells were hardly noticed on G1 (1:2) scaffolds. The cell attachment and cell spreading on scaffolds with different component ratios of GDNF/PLGA fibers to NGF/PDLLA fibers in G2 group (Fig. $6 \mathrm{~g}-\mathrm{k}$ ) were generally much enhanced as compared to scaffolds with corresponding component ratios 


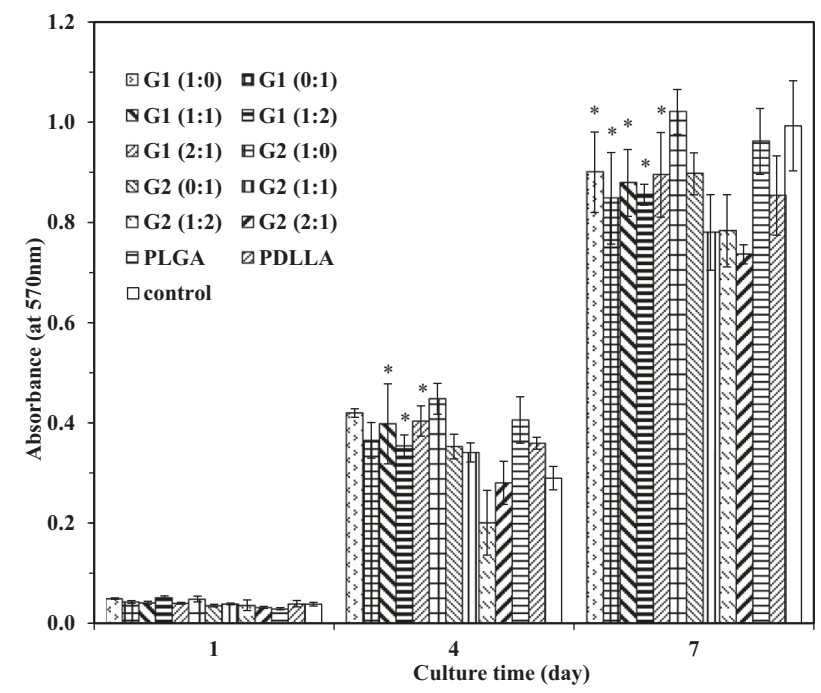

Fig. 5 In vitro cytotoxicity assessment of fibrous scaffolds through MTT tests. Cell proliferation in Group 1 statistically different than that in Group 2 for respective fiber component ratios. ${ }^{*} p<0.05$

of GDNF/PLGA fibers to NGF/PDLLA fibers in G1 group. More cells bearing neurite sprouting and neurite elongation were observed on G2 group scaffolds as compared to their counterpart scaffolds with corresponding component ratios of GDNF/PLGA fibers to NGF/PDLLA fibers in G1 group. However, neurite sprouting and elongation of PC12 cells were hardly observed on G2 (1:2) scaffolds, which was similar with cell morphology on G1 (1:2) scaffolds. Few cells with neurite branching were also noticed on G1 (1:0), G2 (1:0), G2 (0:1), and PLGA scaffolds. However, no neurofilament signal was detected in all scaffolds.

After 4-day culture, PC12 cells randomly distributed on scaffolds with medium cell density as shown in Fig. 7. Cells on different scaffolds exhibited much improved cell adhesion and spreading, neurite outgrowth, and neurite elongation at day 4 as compared to their morphology at day 1 . Relatively weak intracellular neurofilament signals were detected in cells on different scaffolds. Cells on PLGA scaffolds (Fig. 7f) exhibited better cell attachment and cell spreading as compared to those on PDLLA scaffold (Fig. 71). Most of the cells on PDLLA scaffolds were in elongated elliptical shape with neurite protrusions. Cells with elongated morphology and other irregular shapes spread randomly on PLGA scaffolds. Improved neurite sprouting, branching, and extensions were observed in PLGA scaffolds as compared to PDLLA scaffolds. With the stimulation of GDNF and/or NGF, more cells characterized by neurite sprouting, branching, and extensions were seen on growth factor-containing scaffolds (Fig. $7 \mathrm{~g}-1$ ). It was found that neurites extended with scarcely any sprouting and branching in both directions on G2 (0:1) scaffold (Fig. 7h), while neurites protruded randomly with much sprouting and branching on G2 (1:0) scaffold (Fig. 7g). With the increase of component ratio of GDNF/PLGA fibers to NGF/PDLLA fibers in different scaffolds, the phenomenon of neurite sprouting and branching was more obvious. It was worth mentioning that much neurite sprouting, branching, and elongations of PC12 cells occurred on G2 (1:2) scaffolds (Fig. 7j) at day 4, which was dramatically different from cell morphology on G2 (1:2) scaffolds at day 1. Similar phenomena were observed in cells on G1 scaffolds.

After 7-day culture, PC12 cells randomly spread on scaffolds with relatively high cell density and their morphology are shown in Fig. 8. Cells on different scaffolds exhibited further improved cell adhesion and spreading, neurite outgrowth, and neurite elongation at day 7 as compared to their morphology at day 4 . Stronger intracellular neurofilament signals were detected in cells on different scaffolds. Cells were in elongated elliptical shape characterized by partial neurite extensions on both PLGA scaffolds (Fig. 8f) and PDLLA scaffolds (Fig. 81). With the stimulation of GDNF and/or NGF, a large portion of cells characterized by significant neurite extensions appeared on growth factor-containing scaffolds (Fig. 8a-e, g-k). In general, the extent of neurite elongations and branching of PC12 cells was larger on scaffolds with different component ratios of GDNF/PLGA fibers to NGF/PDLLA fibers in G2 group as compared to scaffolds with corresponding fiber component ratios of GDNF/PLGA fibers to NGF/PDLLA fibers in G1 group. More cells characterized with neurite extensions and branching were observed on NGF/PDLLA scaffolds (Fig. 8b, h) as compared to GDNF/PLGA scaffolds (Fig. 8a, g) in both G1 and G2 group. The neurite extensions of cells on NGF/PLGA scaffold appeared to be larger as compared to that on GDNF/PLGA scaffolds in G1 group. However, the neurite length of cells on NGF/PLGA scaffolds appeared to be shorter as compared to that on GDNF/PLGA scaffolds in G2 group. Cells on G1 (1:2) scaffolds and G2 (1:2) scaffolds both exhibited most neurite outgrowth, largest neurite extensions, and also most distinct neurite branching as compared to other scaffolds in G1 group and G2 group, respectively, forming a partially interconnected neurite network. Interestingly, scaffolds composed of other component ratios (1:1 and 2:1) of GDNF/PLGA fibers to NGF/PDLLA fibers induced significantly less neurite outgrowth and shorter neurite extension in both G1 and G2 group.

\subsection{Quantification of neurite length and cell differentiation}

In order to better quantify the cell responses to different scaffolds, normalized neurite length and cell differentiation were determined that are shown in Figs. 9 and 10. The dotted line inserts in Fig. 10 represent neurite length at the level of $28 \mu \mathrm{m}$. 


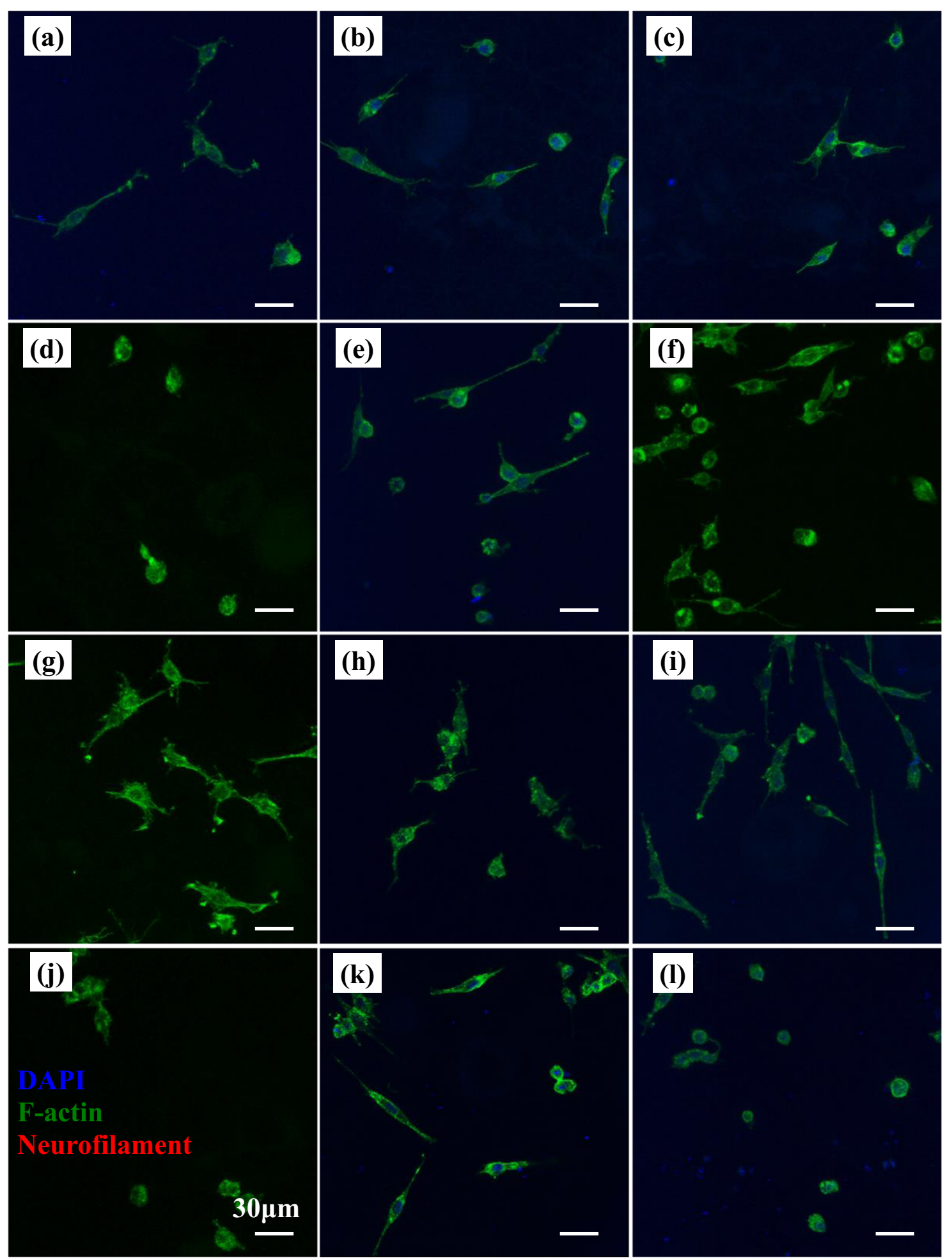

Fig. 6 Morphology of PC12 cells cultured on different scaffolds as revealed under a confocal fluorescent microscope at day 1 . a G1 (1:0) scaffold, b G1 (0:1) scaffold, c G1 (1:1) scaffold, d G1 (1:2) scaffold,

At day 1, it was found that cell differentiation percentages in scaffolds in G2 group were generally higher as compared to those scaffolds with corresponding fiber component ratios of GDNF/PLGA fibers to NGF/PDLLA e G1 (2:1) scaffold, f PLGA scaffold, g G2 (1:0) scaffold, h G2 (0:1) scaffold, i G2 (1:1) scaffold, j G2 (1:2) scaffold, k G2 (2:1) scaffold, and $\mathbf{I}$ PDLLA scaffold

fibers in G1 group. The degree of cell differentiation in PLGA scaffolds and PDLLA scaffolds was much lower as compared with all growth factor-containing scaffolds except G1 (1:2) and G1 (1:2) scaffolds. 


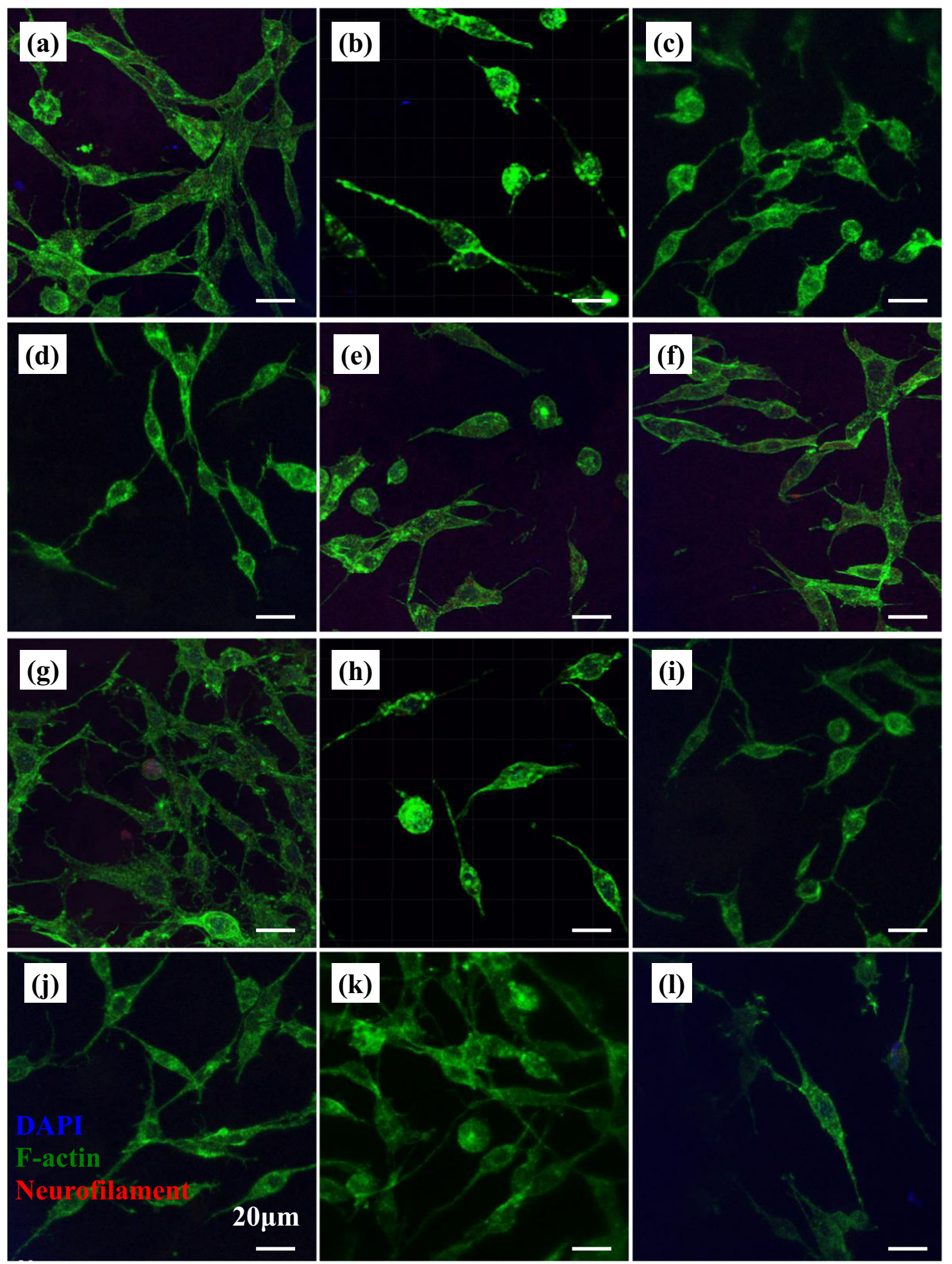

Fig. 7 Morphology of PC12 cells cultured on different scaffolds as revealed under a confocal fluorescent microscope at day 4. a G1 (1:0) scaffold, b G1 (0:1) scaffold, c G1 (1:1) scaffold, d G1 (1:2) scaffold,

The results of normalized neurite length showed that very limited neurite outgrowth and cell differentiation were induced by PLGA and PDLLA fibrous scaffolds at day 1. e G1 (2:1) scaffold, f PLGA scaffold, g G2 (1:0) scaffold, h G2 (0:1) scaffold, i G2 (1:1) scaffold, j G2 (1:2) scaffold, k G2 (2:1) scaffold, and $\mathbf{I}$ PDLLA scaffold

The delivery of growth factors from most of the scaffolds in G1 and G2 groups improved neurite outgrowth and neural differentiation to different extents. 


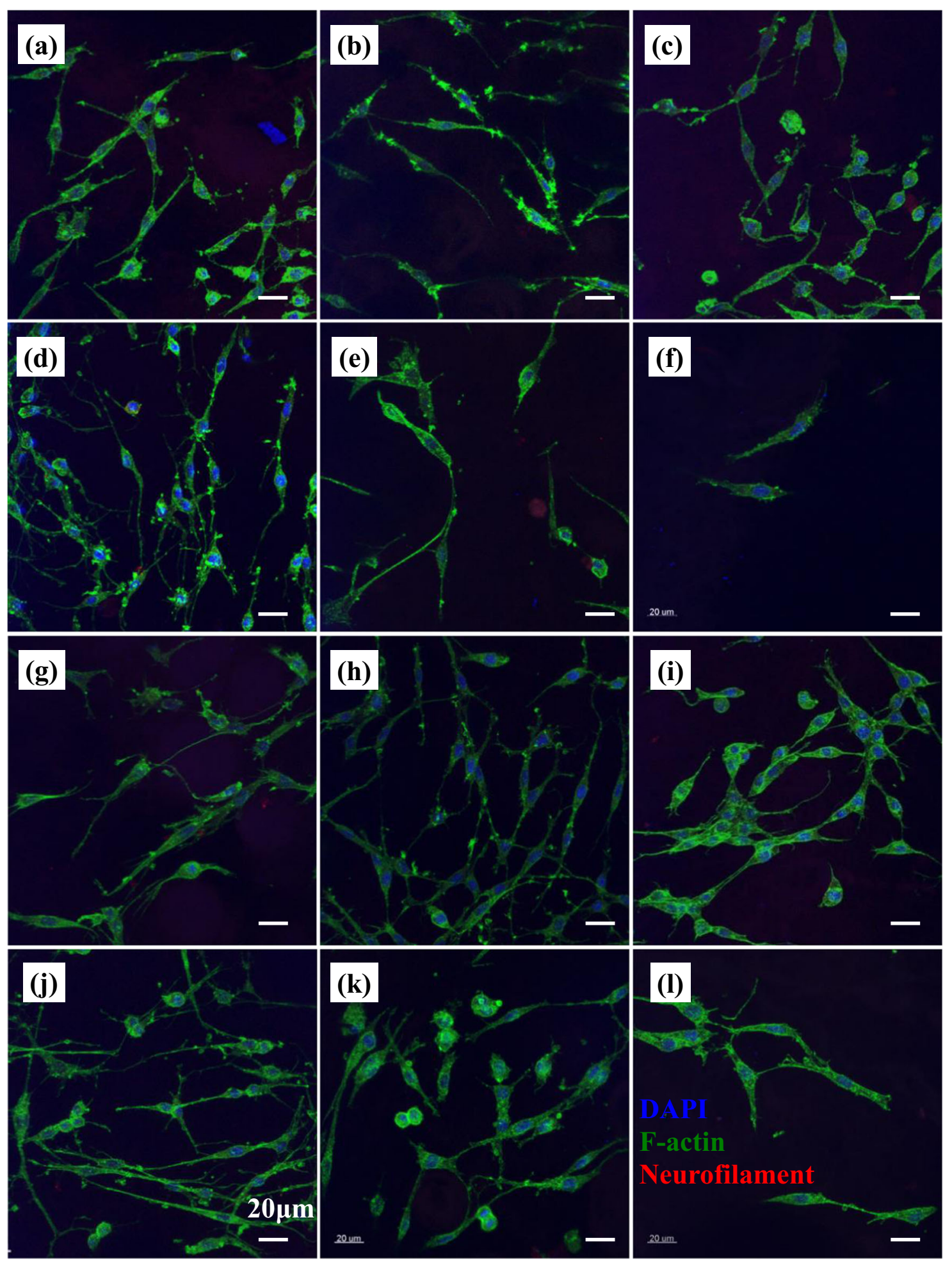

Fig. 8 Morphology of PC12 cells cultured on different scaffolds as revealed under a confocal fluorescent microscope at day 7. a G1 (1:0) scaffold, b G1 (0:1) scaffold, c G1 (1:1) scaffold, d G1 (1:2) scaffold,

At day 4, cell differentiation percentages in scaffolds in G2 group were higher as compared to those scaffolds with corresponding fiber component ratios of GDNF/PLGA fibers e G1 (2:1) scaffold, f PLGA scaffold, g G2 (1:0) scaffold, h G2 (0:1) scaffold, i G2 (1:1) scaffold, j G2 (1:2) scaffold, k G2 (2:1) scaffold, and 1 PDLLA scaffold

to NGF/PDLLA fibers in G1 group. The degree of cell differentiation in PLGA scaffolds and PDLLA scaffolds was much lower as compared with all growth factor-containing 

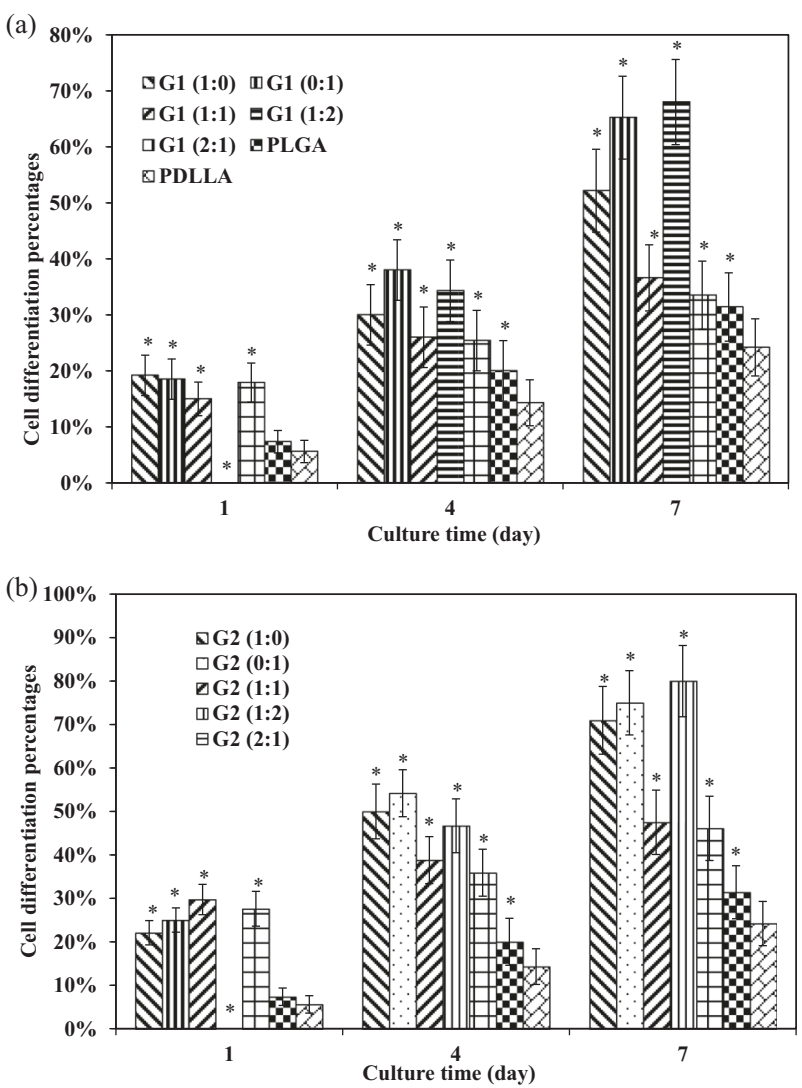

Fig. 9 Cell differentiation of PC12 cells cultured on different scaffolds at days 1, 4, and 7. a G1 group, b G2 group. Cell differentiation statistically different than that in PDLLA control group. ${ }^{*} p<0.05$

scaffolds. Higher degree of cell differentiation was observed in NGF/PDLLA scaffolds as compared to GDNF/ PLGA scaffolds in both G1 and G2 groups. Bicomponent scaffolds with 1:1 and 2:1 fiber component ratios of GDNF/PLGA fibers to NGF/PDLLA fibers induced much lower cell differentiation as compared to monocomponent scaffolds in both G1 and G2 groups. It was worth mentioning that G1 (1:2) scaffolds and G2 (1:2) scaffolds induced the largest increase of cell differentiation percentage from day 1 to day 4 . These results demonstrated that improved neural differentiation and neurite outgrowth was achieved at day 4.

At day 7, cell differentiation percentages in scaffolds in G2 group were higher as compared to those scaffolds with corresponding fiber component ratios of GDNF/PLGA fibers to NGF/PDLLA fibers in G1 group. The degree of cell differentiation in PLGA and PDLLA scaffolds was also much lower as compared with all growth factorcontaining scaffolds. Again, higher degree of cell differentiation was observed in NGF/PDLLA scaffolds as compared to GDNF/PLGA scaffolds in both G1 and G2 groups. Bicomponent scaffolds with 1:1 and 2:1 fiber component ratios of GDNF/PLGA fibers to NGF/PDLLA
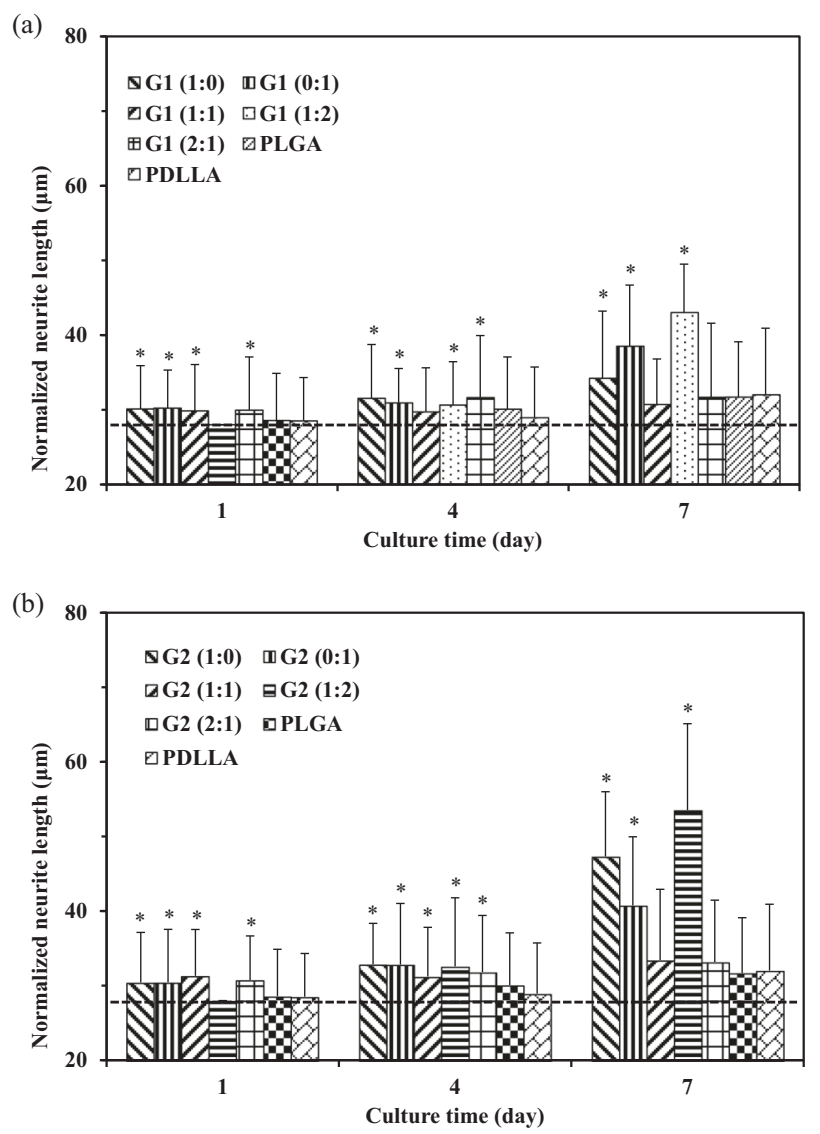

Fig. 10 Normalized neurite length of PC12 cells cultured on different scaffolds at days 1, 4, and 7. a G1 group and PLGA, PDLLA control group, b G2 group and PLGA, PDLLA control group. Neurite protrusion statistically different than that in PDLLA control group. $* p<0.05$

fibers induced much lower cell differentiation as compared to monocomponent scaffolds in both G1 and G2 groups. However, bicomponent scaffolds with 1:2 fiber component ratios of GDNF/PLGA fibers to NGF/PDLLA fibers induced the highest cell differentiation in both G1 and G2 groups. Neurite length was much increased in G1 (1:0), G1 (0:1), G1 (1:2), G2 (1:0), G2 (0:1), and G2 (1:2) scaffolds, while only a slight increase in neurite length was observed in G1 (1:1), G1 (2:1), G2 (1:1), G2 (2:1), PLGA, and PDLLA scaffolds. The longest neurite outgrowth was obtained in bicomponent scaffolds with 1:2 fiber component ratios of GDNF/PLGA fibers to NGF/PDLLA fibers in both G1 and G2 groups. These results revealed that neural differentiation and neurite outgrowth was much improved to different extents and influenced by scaffold components at day 7 .

\subsection{Morphology of cell-scaffold constructs}

The morphology of different cell-scaffold constructs was examined under SEM and are shown in Figs. 11-13. 

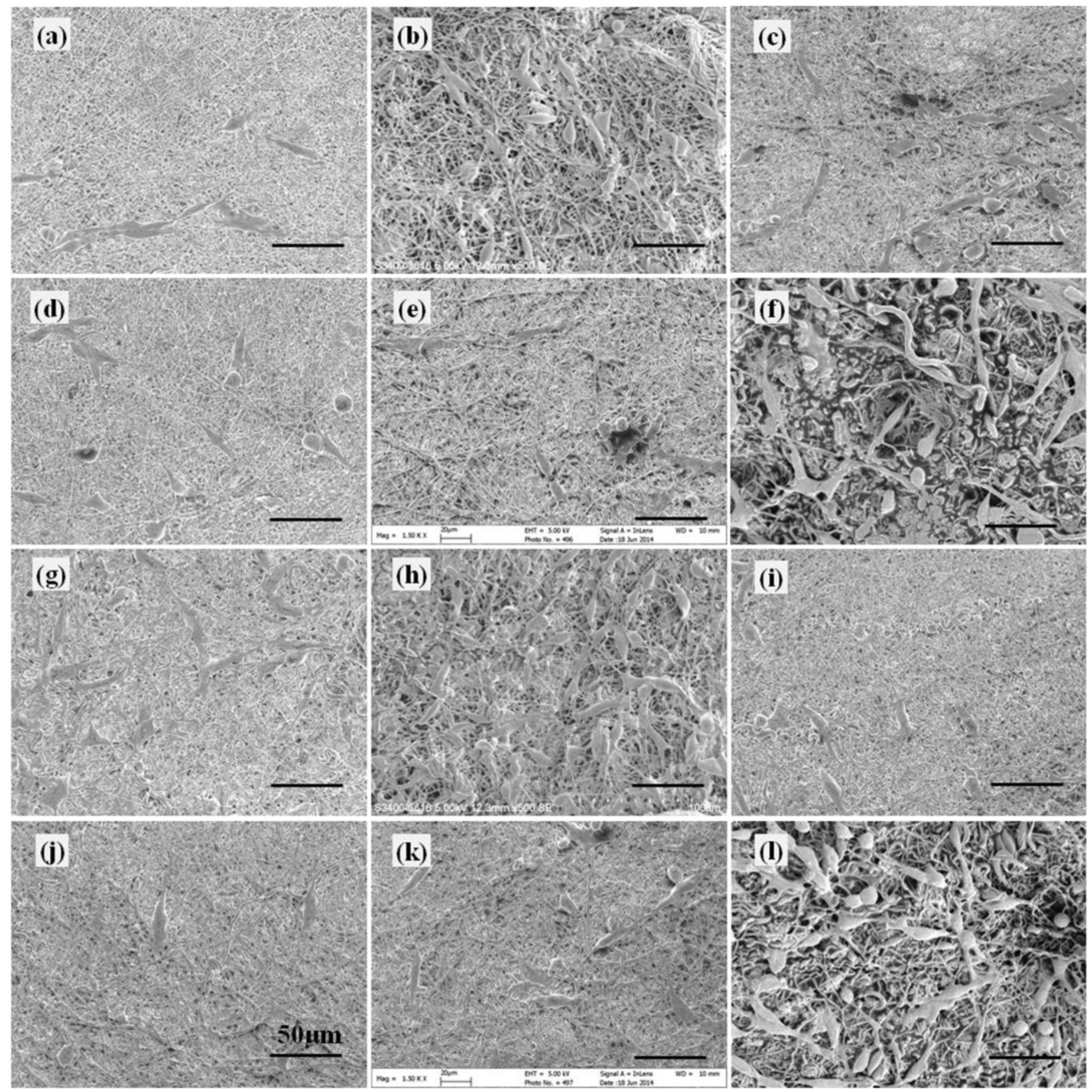

Fig. 11 Morphology of PC12 cells cultured on different scaffolds under SEM at day 1. a G1 (1:0) scaffold, b G1 (0:1) scaffold, c G1 (1:1) scaffold, d G1 (1:2) scaffold, e G1 (2:1) scaffold, f PLGA

It was observed that at day 1, PC12 cells randomly scattered on scaffolds with low cell density. Cells on PLGA scaffolds (Fig. 11f) exhibited better cell attachment and cell spreading as compared to those on PDLLA scaffolds (Fig. 111). Most of the cells on PDLLA scaffolds were in spherical shape with little or no neurite protrusions. A few cells on PLGA scaffolds exhibited elongated elliptical shape and initiated neurite extension. Improved cell attachment and cell spreading on scaffolds in G1 group (Fig. 11a-e) and G2 group (Fig. 11g-k) were observed as scaffold, g G2 (1:0) scaffold, h G2 (0:1) scaffold, i G2 (1:1) scaffold, j G2 (1:2) scaffold, k G2 (2:1) scaffold, and I PDLLA scaffold

compared to that in PDLLA scaffolds. More cells initiating neurite sprouting and exhibiting neurite elongation were found on scaffolds in G1 group except G1 (1:2) scaffolds as compared with both PLGA and PDLLA scaffolds. More cells bearing neurite sprouting and neurite elongation were observed on G2 group scaffolds as compared to their counterpart scaffolds with corresponding component ratios of GDNF/PLGA fibers to NGF/PDLLA fibers in G1 group.

At day 4, cells adhered well and distributed randomly on scaffolds with medium cell density (Fig. 12). Scaffolds with 

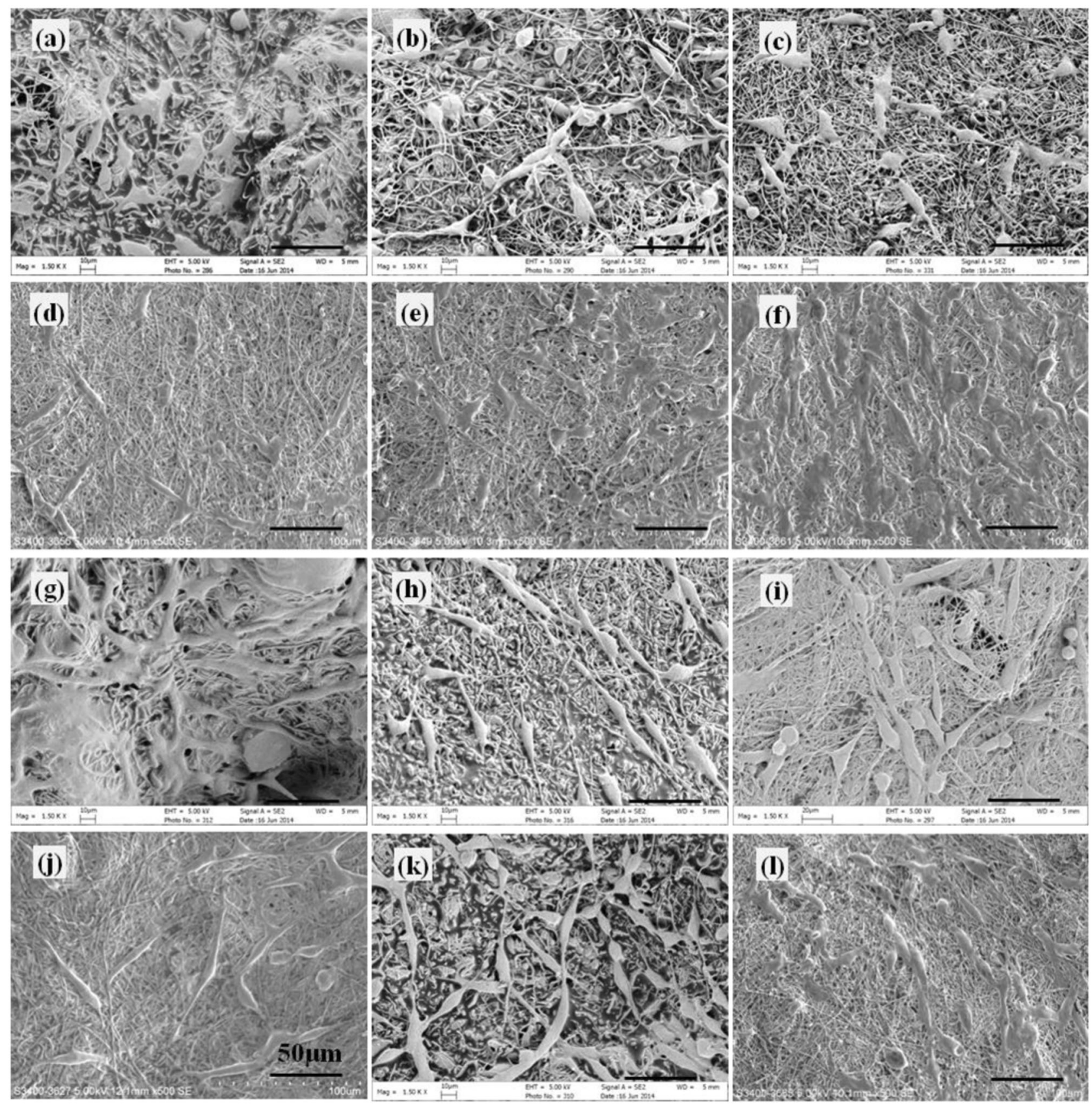

Fig. 12 Morphology of PC12 cells cultured on different scaffolds under SEM at day 4. a G1 (1:0) scaffold, b G1 (0:1) scaffold, c G1 (1:1) scaffold, d G1 (1:2) scaffold, e G1 (2:1) scaffold, f PLGA scaffold, g G2 (1:0) scaffold, h G2 (0:1) scaffold, i G2 (1:1) scaffold, j G2 (1:2) scaffold, k G2 (2:1) scaffold, and I PDLLA scaffold

percentages were obtained in these scaffolds. The phenomenon of neurite outgrowth on scaffolds in G2 group was more evident as compared to scaffolds with corresponding component ratios of GDNF/PLGA fibers to NGF/ PDLLA fibers in G1 group.

At day 7, cells proliferated well and covered a large portion of the surface of scaffolds (Fig. 13). Scaffolds maintained their fibrous structure underneath the cells. With the stimulation of GDNF and/or NGF, more cells 

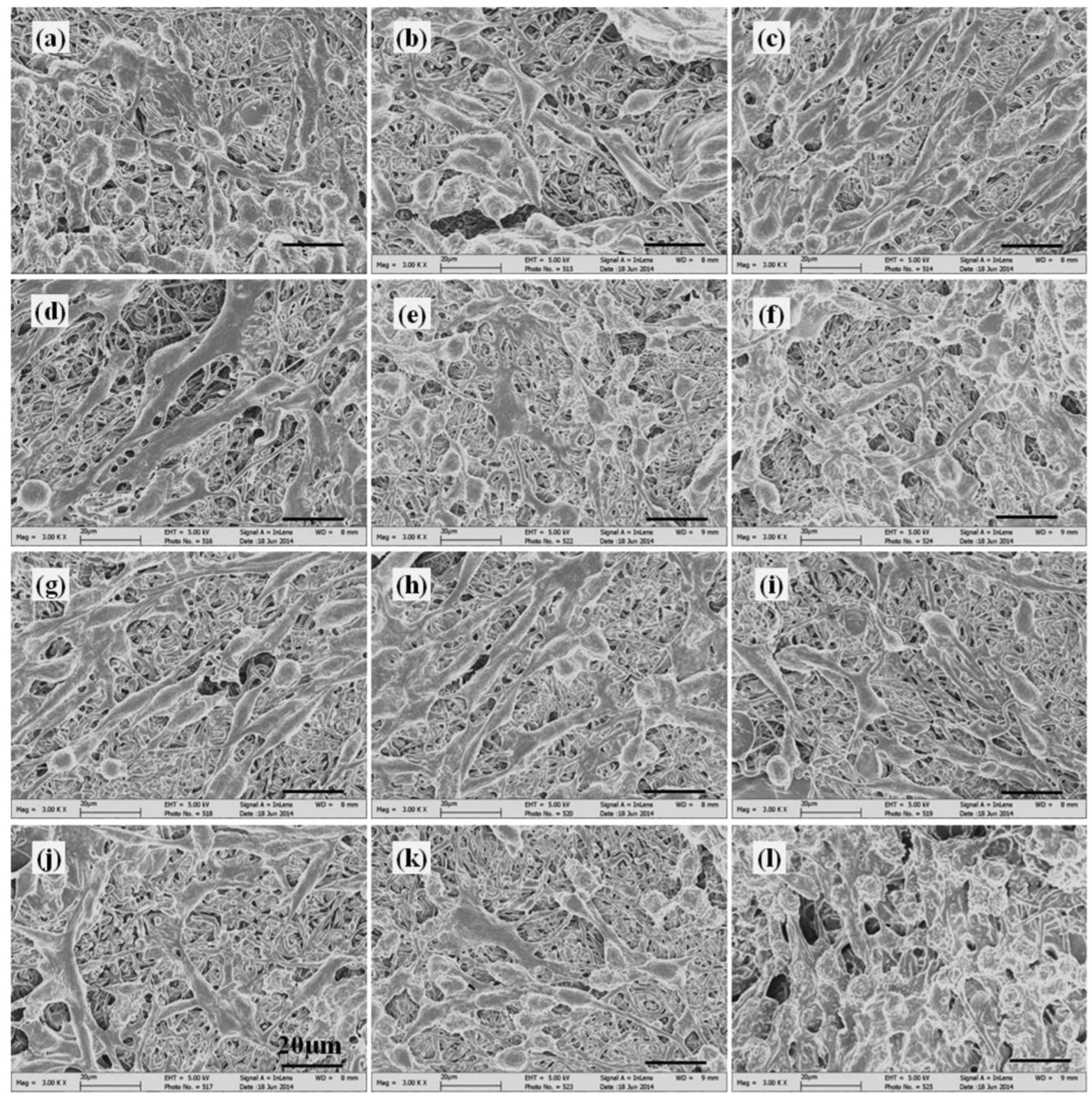

Fig. 13 Morphology of PC12 cells cultured on different scaffolds under SEM at day 7. a G1 (1:0) scaffold, b G1 (0:1) scaffold, c G1 (1:1) scaffold, d G1 (1:2) scaffold, e G1 (2:1) scaffold, f PLGA scaffold, g G2 (1:0) scaffold, h G2 (0:1) scaffold, i G2 (1:1) scaffold, j G2 (1:2) scaffold, k G2 (2:1) scaffold, and I PDLLA scaffold characterized by neurite sprouting, branching, and extensions arose on growth factor-containing scaffolds. The phenomenon of neurite outgrowth on scaffolds in G2 group was more apparent as compared to scaffolds with corresponding component ratios of GDNF/PLGA fibers to NGF/PDLLA fibers in G1 group. In general, the morphological observations of different cell-scaffold constructs at days 1, 4, and 7 by SEM were consistent with the results obtained through CLSM.

\section{Discussion}

Neurotrophic factors play important roles in neuronal survival, proliferation, differentiation, and nerve regeneration, independently or synergistically [1-4]. Different growth factor concentrations are required for different growth factors to generate biologically advantageous outcomes [5]. Sustained and local delivery of neurotrophic factors including GDNF and NGF have been employed to promote 
peripheral nerve regeneration recently $[5,6,8,16-18]$. However, dual and sustained delivery of GDNF and NGF with different release kinetics, which may be very beneficial for enhanced peripheral nerve repair and functional recovery, is rarely investigated.

Electrospun fibers with fiber diameter ranging from nanometers to micrometers are efficient delivery vehicles for various therapeutic biomolecules owing to their high surface area to volume ratio. There is concern about bioactivity loss of biomolecules in electrospun fibers due to their potential deactivation and denaturation that might occur during solution preparation, electrospinning at high voltage, freeze-drying, and sample sterilization [19-21]. Quite a few reports demonstrated that protein released from electrospun scaffolds could induce various cellular responses, indicating that protein activity was at least partially preserved during electrospinning [22-24]. Emulsion electrospinning and coaxial electrospinning techniques could help preserve the bioactivity of vulnerable biomolecules and provide delivery of these biomolecules in a controlled manner $[25,26]$.

In the current investigation, GDNF and NGF were incorporated into robust PLGA and PDLLA fibers, respectively, through emulsion electrospinning (Fig. 1). The "evaporation and stretching-induced de-emulsification" mechanism helped elucidate the formation of core-shell structures [27]. Bicomponent fibrous scaffolds with different GDNF/PLGA fiber to NGF/PDLLA fiber component ratios and different fiber diameters were produced through DSDP-ES. The average fiber diameter in bicomponent scaffolds, which could be taken as a weighted average of fiber diameter of the two types of fibers (GDNF/PLGA fibers to NGF/PDLLA fibers), decreased proportionally with the increase of GDNF/PLGA fiber to NGF/PDLLA fiber ratio, suggesting that the scaffolds had a controllable composition as expected. The strategy of utilizing controlled deposition of fibers to successfully produce bicomponent electrospun scaffolds with tunable composition was also reported [13, 28].

In this investigation, by incorporating growth factors into polymer matrix with different degradation rates and tuning component ratios in bicomponent scaffolds through DSDPES, sustained and concurrent release of GDNF and NGF from fibrous bicomponent scaffolds was achieved. Tunable cumulative release of GDNF and NGF was also obtained by varying GDNF/PLGA fiber to NGF/PDLLA fiber component ratio and fiber diameter in electrospun scaffolds. Following an initial burst release in the first $24 \mathrm{~h}$, sustained release of NGF and/or GDNF from corresponding fibers was found during the release period. The initial burst release was attributed to the growth factor-contained minute reservoirs formed on or close to the surface of fibers during emulsion electrospinning. During emulsion electrospinning, the majority of stretched water droplets moved inward coalesced in the central region and formed the water phase core. However, a minority of water droplets were detained, while the outer layer solidified due to rapid evaporation of organic solvent. These tiny water droplets dwelling on or near the surface of fibers served as reservoir of growth factors and rendered initial burst release through diffusion when the scaffolds were immersed in testing liquid. After the initial burst release, sustained release was obtained that was attributed to either diffusion of growth factor from interior of fibers to immersion liquid through the polymer matrix of fibers or a combination of diffusion and polymer matrix degradation.

The cumulative release amount of NGF decreased proportionally with the increase of GDNF/PLGA fiber to NGF/ PDLLA fiber component ratio in both G1 and G2 groups. Scaffolds with thicker fibers (G1 group) alleviated initial burst release and decreased the release rate of NGF comparing with those with thinner fibers (G2 group). It was also noticed that, at later stage of release tests, release rate of NGF was slightly accelerated in bicomponent scaffolds as compared with that in monocomponent scaffold.

The cumulative release profile of GDNF showed that release of GDNF from bicomponent scaffolds was marginally hindered in comparison with that from their monocomponent counterpart. The slower GDNF release was raised with the increase of PDLLA component in bicomponent scaffolds. More interestingly, a biphasic release profile of GDNF was noticed in G1 (1:0) scaffolds. Following the initial burst release, a sustained release was achieved that may be attributed to diffusion. A remarkable increase of release rate was noticed at around 2 weeks, which was very likely caused by the fusion and erosion of polymer matrix. SEM images of scaffolds at different release periods were employed to help investigate the release mechanism.

Comparing the release profiles of growth factors, it could be seen that biomedical polymers with different wettability and degradation rates could be leveraged to tailor the release behavior of incorporated growth factor. NGF and GDNF were herein incorporated into PDLLA fibers and PLGA fibers, respectively, to obtain different release profile as PLGA was less hydrophobic and had much faster degradation rate than PDLLA [14]. The release rate of GDNF was therefore much faster than that of NGF. Average diameter of electrospun fibers in scaffolds was also a useful control variable to manipulate the release profile of growth factors including the initial burst release and subsequent sustained release. It could not be ignored that in bicomponent scaffolds, the release behavior of either growth factor might be affected to some degree by its counterpart component. It was speculated that hydrophilicity/hydrophobicity of two types of polymer matrix resulted in the 
marginal fluctuation of individual release profile in bicomponent scaffolds. The release of hydrophilic NGF through bicomponent scaffolds was upregulated by less hydrophobic PLGA component; in contrast, the release of hydrophilic GDNF was downregulated by more hydrophobic PDLLA component.

The electrospun fibers in scaffolds had a distribution of fiber diameters and both types of fibers underwent fiber recoiling, swelling, fusion, and minor erosion as release test proceeded. Both diffusion and matrix erosion contributed to release kinetics of protein from biodegradable polymer matrix such as PLGA and PDLLA. Therefore, the release behavior of GFs from electrospun scaffolds could hardly be explained by any simple or generalized model. Although there is no perfect model for modeling the release behavior of NGF or GDNF from bicomponent scaffolds, the results in this study did demonstrate that concurrent and sustained release of NGF and GDNF with tunable amounts and ratios could be achieved.

The influences of these electrospun fibrous scaffolds providing delivery of GDNF and/or NGF with different release kinetics on cell proliferation and neuronal differentiation were investigated using PC12 cells. Biocompatibility is an essential character of tissue engineering scaffolds. Cell proliferation on different scaffolds was investigated by MTT method (Fig. 5). Although cells proliferated significantly from day 1 to day 7 on all scaffolds, different proliferation rates were obtained for different scaffolds. The cell proliferation on growth factor-containing scaffolds may not be as indicative for scaffold cytotoxicity as in experiments where other types of cells were used. The cell responses to scaffolds providing growth factor stimulation were actually a dynamic equilibrium between cell proliferation and differentiation as PC12 cells responded to neurotrophic factors including NGF and GDNF and differentiated into neuron-like phenotypes characterized by halted proliferation and neurite outgrowth [12]. No or negligible cytotoxicity was found for PLGA and PDLLA fibrous scaffolds as both PLGA and PDLLA were biocompatible and biodegradable materials. As no other materials except growth factors were introduced in growth factor-containing scaffolds as compared to PLGA and PDLLA scaffolds, it may be assumed that these growth factor-containing scaffolds also exhibited little or no cytotoxicity.

To test the hypothesis that dual and sustained delivery of GDNF and NGF with different release kinetics can modulate neural differentiation, the morphology of PC12 cells cultured on different scaffolds was investigated and neurite length was measured for determining neural differentiation percentages. Fibrous structures of electrospun scaffolds were maintained (Figs. 11-13). Proliferation or infiltration of PC12 cells into scaffold interior was not commonly observed even though in some scaffolds cells were seen under the surface fibers of scaffolds. Improved cell adhesion and spreading were noticed on PLGA scaffolds as compared to PDLLA scaffolds, which might be attributed to different surface wettability of two types of scaffolds. PLGA fibrous scaffolds had much improved wettability as compared to PDLLA fibrous scaffolds due to hydrophilic glycolic acid segments in PLGA polymer. It is known that surface wettability plays an important role in cell-scaffold interaction including cell adhesion and proliferation. It was reported that an increase in wettability of electrospun fibrous scaffolds increased endothelial cell spreading but decreased cell adhesion [29].

A small portion of PC12 cells differentiated into neuronlike phenotypes characterized by neurite outgrowth along electrospun fibers on both PLGA and PDLLA scaffolds, suggesting that fibrous topography might induce neurite outgrowth and neural differentiation to some extent. This result was consistent with recent studies by other groups that utilized surface topography to enhance cell neural commitment through a process requiring focal adhesion [30-34].

Stimulation of PC12 cells with GDNF and/or NGF released from various scaffolds induced much improved neurite outgrowth and neural differentiation. In general, higher amounts of growth factors induced more cell differentiation and longer neurite extensions. However, the situation of neurite outgrowth and neural differentiation on different growth factor-containing scaffolds varied from one type of scaffold to another. GDNF and NGF released from GDNF/PLGA scaffolds and NGF/PDLLA scaffolds, respectively, both triggered neurite extensions independently. GDNF and NGF released from bicomponent scaffolds with 1:2 component ratio of GDNF/PLGA fibers to NGF/PDLLA fibers induced no neural differentiation at day 1 , but much more neural differentiation at day 4 and highest neural differentiation at day 7. In contrast, GDNF and NGF released from bicomponent scaffolds with 1:1 and 2:1 component ratios of GDNF/PLGA fibers to NGF/PDLLA fibers induced much less neural differentiation at both day 4 and day 7. It appeared that GDNF and NGF released from G1 (1:2) and G2 (1:2) scaffolds exerted a synergistic effect on promoting neural differentiation, while GDNF and NGF released from other bicomponent scaffolds did not. This phenomenon might be attributed to neurotrophic factor dose-dependent neurite outgrowth and signaling pathways of GDNF and NGF [5, 12, 35].

Neurite outgrowth is neurotrophic factor dose-dependent with optimal concentrations in the range of $1-10 \mathrm{ng} / \mathrm{mL}$ as low amounts of NGF are preferred for optimal neurite outgrowth but high amounts of GDNF are favorable for maximum neurite outgrowth [34]. NGF and GDNF stimulate neurite extension through the same mitogen-activated 
protein kinase/extracellular signal-regulated kinase pathway but by binding to their respective tyrosine kinase receptors TrkA and ReT [5, 12]. Both NGF and GDNF can upregulate the expression of their respective receptors and combined NGF/GDNF stimulation can upregulate the expression of two receptors simultaneously, which might result in the observed synergistic effect of neural differentiation on G1 (1:2) and G2 (1:2) scaffolds. However, the molecular mechanisms of the communication pathways among GDNF, NGF, ReT, and TrkA remain further exploration.

\section{Conclusions}

In this study, fibrous bicomponent scaffolds for the dual delivery of growth factors were successfully produced through emulsion electrospinning and DSDP-ES. GDNF and NGF were incorporated into core-shell structured PLGA and PDLLA nanofibers, respectively. Concurrent and sustained release of GDNF and NGF from bicomponent scaffolds was achieved and tunable release profiles were obtained. All of the produced electrospun fibrous scaffolds exhibited no or negligible cytotoxicity. Stimulation of growth factors released from electrospun scaffolds could induce much improved neurite outgrowth and neural differentiation. GDNF and NGF released from scaffolds could induce dose-dependent neurite extensions independently. Dual delivery of neurotrophic factors from bicomponent scaffolds exerted a synergistic effect on promoting neural differentiation, which might be promising for peripheral nerve regeneration.

Acknowledgements This work was supported by the Hong Kong Research Grants Council through a GRF grant (grant no: HKU $718109 E$ ), the National Natural Science Foundation of China (grant No: 51903245), the Guangdong Special Support Plan for High Level Talents of China (grant no: 2015TQ01R546), and the Hubei Natural Science Foundation of China (grant no: 2018CFC874).

\section{Compliance with ethical standards}

Conflict of interest The authors declare that they have no conflict of interest.

Publisher's note Springer Nature remains neutral with regard to jurisdictional claims in published maps and institutional affiliations.

Open Access This article is licensed under a Creative Commons Attribution 4.0 International License, which permits use, sharing, adaptation, distribution and reproduction in any medium or format, as long as you give appropriate credit to the original author(s) and the source, provide a link to the Creative Commons license, and indicate if changes were made. The images or other third party material in this article are included in the article's Creative Commons license, unless indicated otherwise in a credit line to the material. If material is not included in the article's Creative Commons license and your intended use is not permitted by statutory regulation or exceeds the permitted use, you will need to obtain permission directly from the copyright holder. To view a copy of this license, visit http://creativecommons. org/licenses/by/4.0/.

\section{References}

1. Airaksinen MS, Saarma M. The GDNF family: signalling, biological functions and therapeutic value. Nat Rev Neurosci. 2002;3:383-94.

2. Cao X, Shoichet M. Investigating the synergistic effect of combined neurotrophic factor concentration gradients to guide axonal growth. Neuroscience. 2003;122:381-9.

3. Erickson JT, Brosenitsch TA, Katz DM. Brain-derived neurotrophic factor and glial cell line-derived neurotrophic factor are required simultaneously for survival of dopaminergic primary sensory neurons in vivo. J Neurosci. 2001;21:581-9.

4. Price TJ, Louria MD, Candelario-Soto D, Dussor GO, Jeske NA, Patwardhan AM, et al. Treatment of trigeminal ganglion neurons in vitro with NGF, GDNF or BDNF: effects on neuronal survival, neurochemical properties and TRPVI-mediated neuropeptide secretion. BMC Neurosci. 2005;6:4. https://doi. org/10.1186/1471-2202-6-4. PMID: 15667652; PMCID: PMC548274.

5. Madduri S, Papaloïzos M, Gander B. Synergistic effect of GDNF and NGF on axonal branching and elongation in vitro. Neurosci Res. 2009;65:88-97.

6. Chung JH, Kubota H, Ozaki Y, Uda S, Kuroda S. Timingdependent actions of NGF required for cell differentiation. PLoS ONE. 2010;5:2.

7. Fischer J, Kolk A, Wolfart S, Pautke C, Warnke PH, Plank C, et al. Future of local bone regeneration-protein versus gene therapy. J Cranio-Maxillofac Surg. 2011;39:54-64.

8. Roam JL, Nguyen PK, Elbert DL. Controlled release and gradient formation of human glial-cell derived neurotrophic factor from heparinated poly(ethylene glycol) microsphere-based scaffolds. Biomaterials. 2014;35:6473-81.

9. Llorens E, Ibañez H, del Valle LJ, Puiggalí J. Biocompatibility and drug release behavior of scaffolds prepared by coaxial electrospinning of poly(butylene succinate) and polyethylene glycol. Mater Sci Eng C. 2015;49:472-84.

10. Puhl S, Ilko D, Li LH, Holzgrabe U, Meinel L, Germershaus O. Protein release from electrospun nonwovens: Improving the release characteristics through rational combination of polyester blend matrices with polidocanol. Int J Pharmaceutics. 2014;477: 273-81.

11. Tonazzini I, Meucci S, Faraci P, Beltram F, Cecchini M. Neuronal differentiation on anisotropic substrates and the influence of nanotopographical noise on neurite contact guidance. Biomaterials. 2013;34:6027-36.

12. Vaudry D, Stork PJS, Lazarovici P, Eiden LE. Signaling pathways for PC12 cell differentiation: making the right connections. Science. 2002;296:1648-9.

13. Liu CY, Li XH, Xu FY, Cong HB, Li ZX, Song Y, et al. Spatiotemporal release of NGF and GDNF from multi-layered nanofibrous bicomponent electrospun scaffolds. J Mater Sci-Mater Med. 2018;29:102.

14. Liu CY, Wang C, Zhao QL, Li XH, Xu FY, Yao XM, et al. Incorporation and release of dual growth factors for nerve tissue engineering using nanofibrous bicomponent scaffolds. Biomed Mater. 2018;13:044107.

15. Uebersax L, Mattotti M, Papaloizos M, Merkle HP, Gander B, Meinel L. Silk fibroin matrices for the controlled release of nerve growth factor (NGF). Biomaterials. 2007;28:4449-60. 
16. DeGeorge ML, Marlowe D, Werner E, Soderstrom KE, Stock M, Mueller A, et al. Combining glial cell line-derived neurotrophic factor gene delivery (AdGDNF) with L-arginine decreases contusion size but not behavioral deficits after traumatic brain injury. Brain Res. 2011;1403:45-56.

17. de Boer R, Borntraeger A, Knight AM, Hebert-Blouin MN, Spinner RJ, Malessy MJA, et al. Short- and long-term peripheral nerve regeneration using a poly-lactic-co-glycolic-acid scaffold containing nerve growth factor and glial cell line-derived neurotrophic factor releasing microspheres. J Biomed Mater Res Part A. 2012;100A:2139-46.

18. Catrina S, Gander B, Madduri S. Nerve conduit scaffolds for discrete delivery of two neurotrophic factors. Eur J Pharmaceutics Biopharmaceutics. 2013;85:139-42.

19. Briggs T, Arinzeh TL. Examining the formulation of emulsion electrospinning for improving the release of bioactive proteins from electrospun fibers. J Biomed Mater Res Part A. 2014;102:674-84.

20. Volpato FZ, Almodovar J, Erickson K, Popat KC, Migliaresi C, Kipper MJ. Preservation of FGF-2 bioactivity using heparin-based nanoparticles, and their delivery from electrospun chitosan fibers. Acta Biomaterialia. 2012;8:1551-9.

21. Sun B, Long YZ, Zhang HD, Li MM, Duvail JL, Jiang XY, et al. Advances in three-dimensional nanofibrous macrostructures via electrospinning. Prog Polym Sci. 2014;39:862-90.

22. Montero RB, Vial X, Nguyen DT, Farhand S, Reardon M, Pham $\mathrm{SM}$, et al. bFGF-containing electrospun gelatin scaffolds with controlled nano-architectural features for directed angiogenesis. Acta Biomaterialia. 2012;8:1778-91.

23. Zhang H, Jia XL, Han FX, Zhao J, Zhao YH, Fan YB, et al. Dualdelivery of VEGF and PDGF by double-layered electrospun membranes for blood vessel regeneration. Biomaterials. 2013;34:2202-12.

24. Jenkins PM, Laughter MR, Lee DJ, Lee YM, Freed CR, Park D. A nerve guidance conduit with topographical and biochemical cues: potential application using human neural stem cells. Nanoscale Res Lett. 2015;10:1-7.

25. Wang XY, Yuan YH, Huang XC, Yue TL. Controlled release of protein from core-shell nanofibers prepared by emulsion electrospinning based on green chemical. J Appl Polym Sci. 2015; 132:16.

26. Yau WWY, Long HY, Gauthier NC, Chan JKY, Chew SY. The effects of nanofiber diameter and orientation on siRNA uptake and gene silencing. Biomaterials. 2015;37:94-106.

27. Xu XL, Zhuang XL, Chen XS, Wang XR, Yang LX, Jing XB. Preparation of core-sheath composite nanofibers by emulsion electrospinning. Macromol Rapid Commun. 2006;27:1637-42.

28. Bonani W, Motta A, Migliaresi C, Tan W. Biomolecule gradient in micropatterned nanofibrous scaffold for spatiotemporal release. Langmuir. 2012;28:13675-87.

29. Hakamada Y, Ohgushi N, Fujimura-Kondo N, Matsuda T. Electrospun poly(gamma-benzyl-L-glutamate) and its alkali-treated meshes: their water wettability and cell-adhesion potential. J Biomater Sci-Polym Ed. 2012;23:1055-67.

30. Ferrari A, Faraci P, Cecchini M, Beltram F. The effect of alternative neuronal differentiation pathways on $\mathrm{PC} 12$ cell adhesion and neurite alignment to nanogratings. Biomaterials. 2010;31:2565-73.

31. Jiang X, Cao HQ, Shi LY, Ng SY, Stanton LW, Chew SY. Nanofiber topography and sustained biochemical signaling enhance human mesenchymal stem cell neural commitment. Acta Biomaterialia. 2012;8:1290-302.

32. Yang K, Jung H, Lee HR, Lee JS, Kim SR, Song KY, et al. Multiscale, hierarchically patterned topography for directing human neural stem cells into functional neurons. Acs Nano. 2014;8:7809-22.

33. Yin Z, Chen X, Song H-X, Hu J-J, Tang Q-M, Zhu T, et al. Electrospun scaffolds for multiple tissues regeneration in vivo through topography dependent induction of lineage specific differentiation. Biomaterials. 2015;44:173-85.

34. Yoo HS, Kim TG, Park TG. Surface-functionalized electrospun nanofibers for tissue engineering and drug delivery. Adv Drug Deliv Rev. 2009;61:1033-42.

35. Fine EG, Decosterd I, Papaloizos M, Zurn AD, Aebischer P. GDNF and NGF released by synthetic guidance channels support sciatic nerve regeneration across a long gap. Eur $\mathrm{J}$ Neurosci. 2002;15:589-601. 